\title{
Evidence of Counter-Streaming Ions near the Inner Pole of the HERMeS Hall Thruster
}

\author{
Wensheng Huang ${ }^{*}$, Hani Kamhawi ${ }^{\dagger}$, and Daniel A. Herman ${ }^{\ddagger}$ \\ National Aeronautics and Space Administration Glenn Research Center, Cleveland, OH, 44135, USA
}

\begin{abstract}
NASA is continuing the development of a $12.5-\mathrm{kW}$ Hall thruster system to support a phased exploration concept to expand human presence to cis-lunar space and eventually to Mars. The development team is transitioning knowledge gained from the testing of the government-built Technology Development Unit (TDU) to the contractor-built Engineering Test Unit (ETU). A new laser-induced fluorescence diagnostic was developed to obtain data for validating the Hall thruster models and for comparing the behavior of the ETU and TDU. Analysis of TDU LIF data obtained during initial deployment of the diagnostics revealed evidence of two streams of ions moving in opposite directions near the inner front pole. These two streams of ions were found to intersect the downstream surface of the front pole at large oblique angles. This data points to a possible explanation for why the erosion rate of polished pole covers were observed to decrease over the course of several hundred hours of thruster operation.
\end{abstract}

\begin{tabular}{|c|c|c|c|}
\hline \multicolumn{4}{|c|}{ Abbreviations } \\
\hline AEPS & $=$ Advanced Electric Propulsion System & LIF & Laser-Induced Fluorescence \\
\hline AOI & $=$ Angle of incidence & MCD & $=$ Mean Channel Diameter \\
\hline CEX & $=$ Charge-exchange & OFPC & $=$ Outer Front Pole Cover \\
\hline ETU & $=$ Engineering Test Unit & RFC & $=$ Reference Firing Condition \\
\hline FWHM & $=$ Full-Width-at-Half-Maximum & SEP & Solar Electric Propulsion \\
\hline GRC & $=$ Glenn Research Center & SNR & $=$ Signal-to-Noise Ratio \\
\hline HERMeS & $=$ Hall Effect Rocket with Magnetic & STMD & $=$ Space Technology Mission Directorate \\
\hline & Shielding & TDM & $=$ Technology Demonstration Mission \\
\hline IFPC & $=$ Inner Front Pole Cover & TDU & $=$ Technology Development Unit \\
\hline IPS & $=$ Ion Propulsion System & VF & $=$ Vacuum Facility \\
\hline JPL & $=$ Jet Propulsion Laboratory & WT & $=$ Wear Test \\
\hline
\end{tabular}

\section{Introduction}

- OR missions beyond low Earth orbit, spacecraft size and mass can be dominated by onboard chemical propulsion F systems and propellants that may constitute more than 50 percent of spacecraft mass. This impact can be substantially reduced through the utilization of Solar Electric Propulsion (SEP) due to its substantially higher specific impulse. Studies performed for NASA's Human Exploration and Operations Mission Directorate (HEOMD) and Science Mission Directorate have demonstrated that a $40 \mathrm{~kW}$-class SEP capability can be enabling for both near term and future architectures and science missions. ${ }^{1}$

Since 2012 NASA has been developing a 14-kW Hall thruster electric propulsion string that can serve as the building block for realizing a 40-kW-class SEP capability. NASA continues to evolve a human exploration approach to expand human presence beyond low-Earth orbit and to do so, where practical, in a manner involving international, academic, and industry partners. ${ }^{2}$ NASA publicly presented a phased exploration concept at the HEOMD Committee of the NASA Advisory Council meeting on March 2017. ${ }^{3}$ NASA presented an evolutionary human exploration architecture, depicted in Fig. 1, to expand human presence deeper into the solar system through a phased approach

\footnotetext{
${ }^{*}$ Ion Propulsion System Diagnostics Lead, EP Systems Branch, wensheng.huang@nasa.gov, Associate Fellow.

† Ion Propulsion System Test Lead, EP Systems Branch, hani.kamhawi-1@nasa.gov, Associate Fellow.

‡ Ion Propulsion System Lead, EP Systems Branch, daniel.a.herman@nasa.gov, Associate Fellow.
} 
including cis-lunar flight testing and validation of exploration capability before crewed missions beyond the Earth-Moon system and eventual crewed Mars missions. One of the key objectives is to achieve human exploration of Mars and beyond through the prioritization of those technologies and capabilities best suited for such a mission in accordance with the stepping stone approach to exploration. ${ }^{4}$ High-power solar electric propulsion is one of those key technologies that have been prioritized because of its significant exploration benefits. A high-power, $40 \mathrm{~kW}$ class Hall thruster propulsion system provides significant capability and represents, along with flexible blanket solar array technology, a readily scalable technology with a clear path to much higher power systems.

The 14-kW Hall thruster system development, led by the NASA Glenn Research Center (GRC) and the Jet Propulsion Laboratory (JPL), began with maturation of the high-power Hall thruster and power processing unit. In particular, the Hall thruster is called Hall Effect Rocket with Magnetic Shielding (HERMeS) Technology Development Unit (TDU). The technology development work has transitioned to Aerojet Rocketdyne via a competitive procurement selection for the Advanced Electric Propulsion System (AEPS). The AEPS contract includes the development, qualification, and production of multiple flight 14-kW electric propulsion string deliveries. The AEPS Electric Propulsion string consists of the Hall thruster, power processing unit (including digital control and interface functionality), xenon flow controller, and associated intra-string harnesses. During the development phase of the AEPS, Engineering Test Unit (ETU) Hall thrusters are being produced for testing.

To minimize technical risks associated with ETU development, the NASA team is performing risk reduction activities on the HERMeS TDUs. ${ }^{6} 7$ The specifications for the 12.5-kW HERMeS are enhanced compared to the current state of the art. ${ }^{6}$ Characteristics of the thruster include high system efficiency ( $\geq 57 \%$ ), high specific impulse (up to $3000 \mathrm{~s}$ ), and high propellant throughput capability (3400 kg). Additionally, HERMeS was designed to deliver similar system efficiency at a more modest specific impulse of 2000 seconds. High specific impulse operation supports mission concepts with high total-impulse requirements like deep-space exploration missions, while the modest specific impulse operation is beneficial for time-critical operations like LEO to GEO orbit-raising.

A series of tests were performed on three HERMeS TDUs. ${ }^{7}$ Figure 2 shows a diagram of the testing on the HERMeS TDUs thus far. ETU testing is scheduled to begin after the testing shown in this figure. Testing on the TDU1 included the propellant uniformity test, ${ }^{8}$ magnetic shielding characterization test, ${ }^{9}$ performance characterization test (PCT), ${ }^{10-12}$ thermal characterization test (TCT), ${ }^{13,}{ }^{14}$ facility effect characterization test (FECT), ${ }^{10,12,15}$ and the first wear test (WT) campaign. The PCT, TCT, and FECT were performed with a single test setup. The first wear test campaign, completed in 2016, included the electrical configuration characterization test (ECCT), ${ }^{16,}{ }^{17}$ two short duration tests, ${ }^{18}$ and a long duration wear test. ${ }^{17,} 18$ TDU1 was then used in a number of short duration wear tests ${ }^{19}$ (part of the second wear test campaign), laser-induced

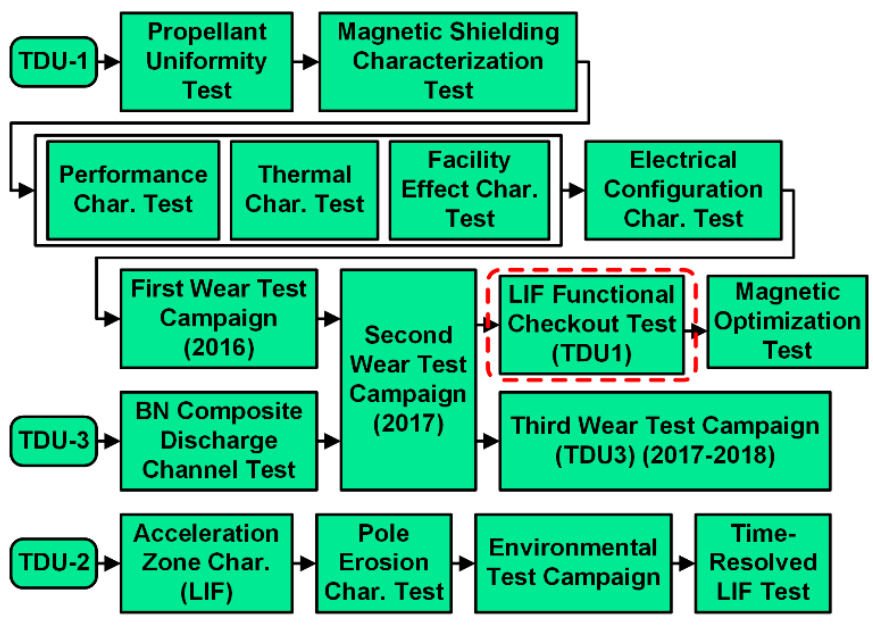

Figure 2. A diagram of the TDU test campaigns.

fluorescence (LIF) functional checkout test, ${ }^{20}$ and magnetic optimization test. ${ }^{21}$ TDU2 underwent the acceleration zone characterization test, ${ }^{22}$ pole erosion characterization test, ${ }^{23}$ environmental test campaign, ${ }^{24}$ and time-resolved LIF 
test. ${ }^{25}$ TDU3 was used in another performance characterization test, which involved boron nitride composite discharge channel, ${ }^{26}$ the second wear test campaign, ${ }^{19}$ and the third wear test campaign. ${ }^{27,}{ }^{28}$ The third wear test campaign included a long duration wear test of the TDU3 ${ }^{28}$ The bulk of this article is focused on the findings from the LIF functional checkout test performed on TDU1.

During an early risk reduction test performed on the H6 Hall thruster, the plasma in the discharge channel was found to be strongly perturbed by the injection of physical probes into the discharge channel. ${ }^{29}$ LIF techniques can obtain the discharge channel plasma data needed for model validation without perturbing the plasma. In particular, spatial maps of the ion velocity distribution functions (VDFs) can be used to infer the mobility profile inside of the discharge channel and is an excellent metric for both model validation and comparing characteristics between the TDU and ETU.

The main objectives of the LIF functional checkout test were to check out the functionalities of a new LIF diagnostics system for use with high-power engineering Hall thrusters and to collect comprehensive data sets for comparison between the TDU and ETU, which will be tested later. During this test, a complete set of ion VDF maps were obtained of the TDU across various discharge voltages, discharge powers, magnetic field strengths, and background pressures. Interrogation zones included inside the discharge channel, in the near-field of the channel exit, and downstream of the pole covers. Prior publications described initial results showing evidence of low energy, highdivergence ion population in the discharge plasma. ${ }^{20}$ This article will focus on evidence of counter-streaming ions downstream of the inner pole covers. This article will also describe an updated LIF analysis routine that accounts for Zeeman hyperfine splitting as well as provides updated LIF results.

\section{Experimental Setup}

To simplify plot labeling, throttle points are labeled by discharge voltage and discharge power. A label that says "300-6.3" refers to the throttle point with a discharge voltage of $300 \mathrm{~V}$ and a discharge power of $6.3 \mathrm{~kW}$.

Unless otherwise noted, all spatial positions around the thruster are normalized based on the region of interest. For the thruster discharge channel, radial positions are normalized by the discharge channel width, where $\mathrm{R}=0$ is the inner wall, $\mathrm{R}=1$ is the outer wall, $\mathrm{Z}=0$ is the exit plane as defined by the inner front pole cover downstream surface, and $\mathrm{Z}$ is positive in the downstream direction. Similarly, data near the inner and outer front pole covers are normalized so that $\mathrm{R}=0$ and $\mathrm{R}=1$ correspond to the inner and outer radial edges, respectively, of the region of interest.

\section{A. Thruster and Test Matrix}

All data presented in this work were collected with the HERMeS TDU1. The HERMeS TDU was designed to be a $12.5 \mathrm{~kW}, 3000 \mathrm{~s}$, magnetically-shielded Hall thruster. The thruster had been operated over discharge voltages ranging from 300 to $800 \mathrm{~V}$, corresponding to a specific impulse range of 2000 to $3000 \mathrm{~s}$ at full power. The thruster had also been throttled over discharge powers ranging from 0.6 to 12.5 $\mathrm{kW} .{ }^{10}$ The cathode mass flow rate was maintained at $7 \%$ of the anode mass flow rate.

Thruster magnet coils were energized so that the magnetic shielding topology was always maintained. The only degree of freedom in the magnetic field setting was the strength of the magnetic field. Peak radial magnetic field strength along the discharge channel centerline was chosen as the reference when referring to the strength of the magnetic field. A single magnetic field strength value was chosen as the nominal value for all operating conditions. This value was set to provide the highest thruster efficiency possible while maintaining margin against oscillation mode transitions. Figure 3 shows a picture of the NASA HERMeS TDU1 on the LIF test stand.
Table 1. Table of Reference Firing Conditions.

\begin{tabular}{ccc}
\hline Label & $\begin{array}{c}\text { Discharge } \\
\text { voltage, } \mathrm{V}\end{array}$ & $\begin{array}{c}\text { Discharge } \\
\text { power, } \mathbf{k W}\end{array}$ \\
\hline $300-2.7$ & 300 & 2.70 \\
$* 300-6.3$ & 300 & 6.25 \\
$* 400-8.3$ & 400 & 8.33 \\
$* 500-10.4$ & 500 & 10.42 \\
$* 600-12.5$ & 600 & 12.50 \\
$630-13.1$ & 630 & 13.12 \\
\hline
\end{tabular}

*RFCs that were the focus of the testing described in this paper.

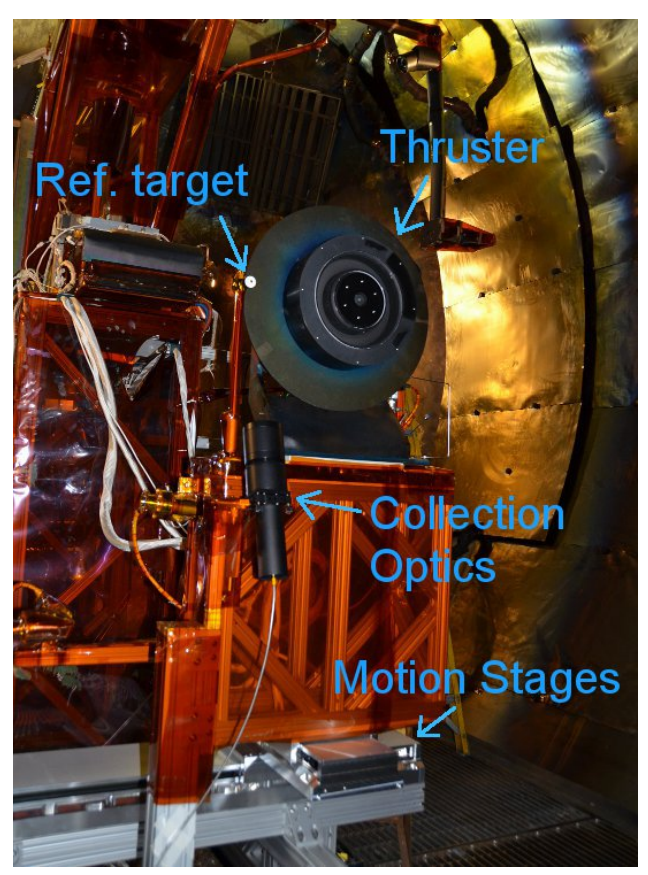

Figure 3. NASA HERMeS TDU1 and thrust stand setup. 
The specifications for the TDUs included seven Reference Firing Conditions (RFCs), which were throttle points that would be used in all TDU testing. Though the full operational range of the TDUs extends well beyond the RFCs, testing was constrained to the RFCs to limit testing cost. Table 1 lists the RFCs. The testing described in this paper focused on four of the RFCs, which are marked with asterisks.

For the testing described in this paper, the thruster body was isolated from the test stand and connected to the cathode. Prior testing had determined that this cathode-tied configuration was associated with low pole cover erosion and can be readily implemented in flight. ${ }^{16,17}$

Thruster telemetry collected during testing showed that the HERMeS TDU1 was operating the same way as prior TDU1 testing in Vacuum Facility 6. ${ }^{30}$

\section{B. Test Facility}

Testing was performed in Vacuum Facility 6 at NASA GRC. This cylindrical facility is $7.6 \mathrm{~m}$ in diameter, $21.3 \mathrm{~m}$ long, and was evacuated with a set of cryo-pumps. The thruster was mounted on a test stand that can be moved horizontally with two cross-mounted motion stages. Figure 3 shows the thruster mounted on the test stand. Also in the figure are the reference target used for laser alignment, the collection optics, and the motion stages that move the test stand.

To accommodate the movement of the thruster while supplying high-purity propellant to the thruster, a new propellant delivery approach was developed. Key positions along stainless steel tubing were bent into coils that formed joints. Each joint provided enough flexibility to the tubing to allow movement without causing plastic deformation. The tubing was then wrapped with heat tape for bakeout to ensure high-purity propellant delivery.

Background pressure near the thruster was monitored with two ion gauges, which were calibrated on xenon against a spinning rotor gauge. Gauge readings were corrected for temperature and direction relative to background flux via methods described in Yim and Burt. ${ }^{31}$ Uncertainty in the calculated pressure was dominated by plasma-induced noise, electronic noise, and uncertainties associated with correction method. Total uncertainty in pressure is estimated to be $10 \%$ to $15 \%$ of the reading. The background pressure near the thruster for the testing described in this paper was $1.2 \times 10^{-5}$ Torr.

Research-grade xenon propellant was supplied via commercially available mass flow controllers to the thruster and cathode. These mass flow controllers were calibrated using research-grade xenon prior to testing. Typical uncertainty of measurement was $\pm 1 \%$ of reading.

Electrical power was supplied to the thruster with commercially available power supplies. Separate power supplies supported the main discharge, cathode heater, keeper, inner magnet, and outer magnet. An electrical filter was placed between the thruster and the discharge power supply. All power supplies and the filter were located outside of the vacuum facility.

\section{Diagnostics}

The LIF velocimetry scheme used in the LIF functional checkout test excites the XEII $834.953 \mathrm{~nm}$ (vac) transition and collects fluorescence from the $542.066 \mathrm{~nm}$ (vac) transition. Figure 4 shows a diagram of the LIF scheme used. This singly-charged xenon ion transition has an unusually narrow hyperfine structure that cannot be easily resolved even when probed with special techniques. ${ }^{32}$ In a previous study, the pi-polarized Zeeman Effect ${ }^{\S}$ for this transition was found to be negligible. ${ }^{33}$ The implication of the prior work is that if pi-polarization can be maintained, the broadening in the VDF obtained in the discharge channel of a Hall thruster is at most $4-5 \% .{ }^{32}$ However, for the TDU and ETU, regions of interest included regions with high magnetic field strength and where the local directions of the magnetic field were often out of alignment with the polarization directions of the laser beams. Instead of trying to maintain pi-polarization in some regions but not others, the decision was made to set the polarization direction of both side injection axes so that those scans are always purely sigma-polarized. The Zeeman-broadened data would then be corrected in post processing using a simplified linear model developed by Huang in a prior work. ${ }^{33}$ Polarization direction of the axial injection axis was set to allow pi-polarization throughout most of the discharge channel while accepting increased broadening in certain regions. Within these regions, VDF width data from the side injection axes were used instead.

\footnotetext{
$\S$ In Zeeman Effect, photons are considered to be pi-polarized if their polarization is parallel to the direction of the external magnetic field experienced by the interacting particle. Photons are considered to be sigma-polarized if their polarization is perpendicular to the direction of the external magnetic field. If the direction of polarization is in between, quantum physics can be used to determine the probability that a given photon will interact as if it were sigma versus pi-polarized. However, this is not a simple process. In Hall thruster LIF applications where Zeeman Effect is important, in-between polarization should be avoided in order to reduce uncertainty.
} 
The laser used in this LIF test was a taper-amplified diode laser that output up to $500 \mathrm{~mW}$ at $835 \mathrm{~nm}$. Wavelength was monitored via a Fizeau-type wavemeter and an optogalvanic cell. The laser beam entering the optogalvanic cell was mechanically chopped at $\sim 1.6 \mathrm{kHz}$. The laser beam was also monitored with photodiode to track the variation in laser power. The laser beam was split into three branches. Each branch passed through an electro-optical modulator and was collimated into an optical fiber. A modulation frequency study showed that the signal-to-noise ratio (SNR) optimized at around $300 \mathrm{kHz}$ to $350 \mathrm{kHz}$ in modulation frequency.

Figure 5 shows a diagram of the optics setup inside the vacuum facility. Three sets of injection optics where deployed. The optical fibers from the air-side setup were sent to each of the three sets of injection optics. Each set of injection optics had two motors that allowed remote control of the tilt and pan. The optics on axis 1, the axial axis, was protected from most of the heat of the plasma by a shield. Additionally, the support structure for the axis 1 optics was equipped with an internal cooling line connected to a chiller. The thruster was mounted to the motion stages that provide radial and axial movements. A reference target was mounted at a known distance from the thruster in the same plane as the three injected laser beams. Two cameras monitored the positions of the injected laser beams relative to the reference target. The collection optics were mounted $70^{\circ}$ out of the injection plane. An optical fiber carried fluorescence signal from the collection optics out of the vacuum facility. The spatial resolution of the measurements was limited by the beam waist of the injection beams and the viewing cone of the collection optics to approximately $1 \mathrm{~mm}$ in size.

The light from the collection optical fiber was collimated into a monochromator and sent to a photomultiplier. The photomultiplier current was converted to voltage via a high-speed trans-impedance amplifier. The output voltage signal was coupled into three digital lock-in amplifiers. A fourth digital lock-in amplifier measured the signal from the optogalvanic cell. A computer controlled the movement of various stages, swept the laser wavelength, and recorded the various output signals. Lock-in amplifier time constant varied from $300 \mathrm{~ms}$ to $1 \mathrm{~s}$.

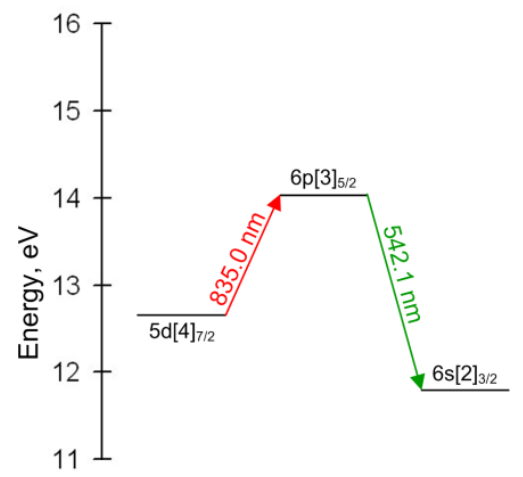

Figure 4. Transition diagram for Xe II LIF at $834.953 \mathrm{~nm}$ (vac).

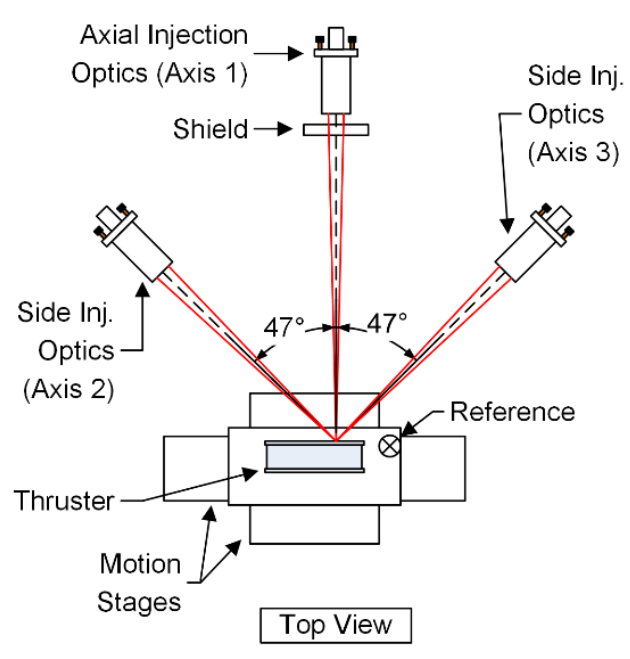

(a)

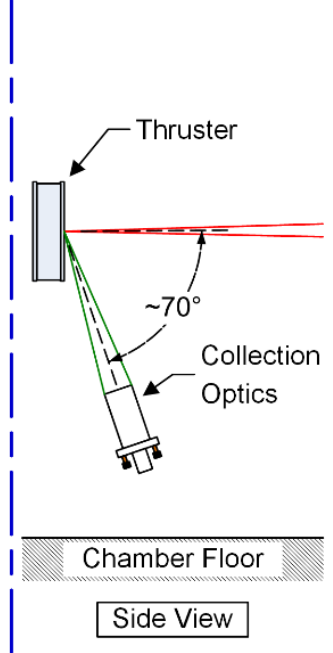

(b)

Figure 5. Vacuum-side optical setup.

Due to the small size of the interrogation zone relative to the length scale of the rest of the vacuum facility, shifts in laser alignment over the course of the experiment can easily take the injected beams and the collection optics out of alignment if not corrected for. The new LIF system uses a reference pin, an image disc, and two cameras to track the position of the laser beams relative to the thruster. Since the reference pin is $1 \mathrm{~mm}$ in diameter, change in alignment as small as $0.1 \mathrm{~mm}$ can be detected by looking at the intensity of the laser light reflected off of the alignment pin. If the alignment drifts by more than $1 \mathrm{~mm}$, the laser beams will fall on the image disc and can be seen in the cameras. The cameras had their IR-cut filters removed so that they can see the near-IR laser beam.

American Institute of Aeronautics and Astronautics 


\section{Data Analysis}

\section{A. Analysis Method}

A saturation study was performed at the beginning of the test campaign to pick out injection laser power that balances saturation broadening and SNR (i.e. high laser intensity leads to higher SNR but also more saturation broadening). The amount of broadening was kept to below $10 \%$.

The first step in the data analysis was to convert readings from the wavemeter and optogalvanic cell into frequency shift from the stationary transition frequency. This frequency shift was sometimes referred to as the detuning. The detuning was then converted into a velocity scale.

The intensity data was corrected for changes in laser power by using a combination of photodiode and thermopile measurements. First, the laser power as measured by the thermopile and the photodiode were collected in a controlled study. Then, the photodiode measure during data acquisition was corrected by the results of the controlled study to provide an accurate measurement of the laser power. This correction removed artificial features that may have been created in the intensity data due to variations in laser power as the wavelength varied.

Next, curve-fits were performed on the intensity versus the velocity. Three different types of curve-fits were used including skew-normal, Gaussian, and Two-Gaussian functions. Figure 6 shows an example of skew-normal curve-fit. Figure 7 shows an example of Two-Gaussian curvefit. Two-Gaussian fits were used when skew-normal and Gaussian distributions do not adequately capture the lineshape.

For the side injection axis, which were purely sigma-polarized, Zeeman Effect on the hyperfine structure was corrected by applying a simple linear model for the XEII $834.953 \mathrm{~nm}$ (vac) transition. ${ }^{33}$ The model is reproduced here in the form of Eq. (1) for convenience.

\section{Zeeman splitting in $\mathrm{MHz}=2.7273 \times$ Magnetic field strength in Gauss}

To apply the model, magnetic field simulation of the TDU was used. This magnetic field simulation was validated using magnetic field measurements of the three TDUs. At each location where LIF data was taken, the magnetic field strength in the axial-radial plane was extracted from the simulation and inputted into Eq. (1). The resulting splitting amount was convoluted with the curve-fit and then compared to the lineshape. Once a set of acceptable curve-fit parameters were determined, the curve-fit without the Zeeman Effect was taken to be the final result of the Zeeman Effect correction. For a brief explanation of convolution, please see this prior work. ${ }^{34}$ On average, the Zeeman Effect correction reduced the width of the VDFs by about 3-5\%. However, in regions of high magnetic field, the correction reduced the width of the VDFs by as much as $40 \%$.

Once the curve-fits were performed, averaged velocities and full-width-at-half-maximum (FWHM) velocities were calculated. If a Two-Gaussian fit was used, additional analyses were performed depending on the location associated with the data. For data found in the acceleration zone of the thruster, where large changes in velocity have been observed, the Two-Gaussian fits were analyzed as if they were a single population spread out by plasma potential oscillations. For data found near the discharge channel but downstream of the acceleration zone, the two peaks found were assumed to be two distinct populations. In such a case, the averaged energy and direction of the two peaks were separately calculated and the results compared to far-field retarding potential analyzer data to confirm that they were indeed two separate populations. A prior publication contains greater detail of how the low energy population was identified and speculated to be charge-exchange (CEX) ions. ${ }^{20}$ For data found near the inner pole cover, the ions were initially analyzed as a single population affected by Zeeman Effect. ${ }^{20}$ Incorporation of Zeeman Effect correction has shown the initial analysis approach to be incorrect. New analysis results presented in this article suggest that there were two distinct ion populations near the inner pole cover.

American Institute of Aeronautics and Astronautics 


\section{B. Uncertainty Analysis}

The uncertainty in position was dominated by the size of the interrogation zone and the drift in alignment of the optics. The alignment procedure used in this LIF test rejected data where alignment drifted by more than $0.5 \mathrm{~mm}$ from the reference.

The SNR was an important metric in assessing uncertainty in the data. The SNR was defined as the ratio of the peak signal divided by the standard deviation of the noise. Typically, any trace with an SNR of 3 or less was considered to be statistically insignificant. At this value of SNR, any peak present was barely detectable against the noise. Since three injection axes were used, if the SNR was low on one axis, a velocity vector could still be calculated from the remaining two axes. Where reliable data was available from all three axes, calculations of the axial velocity were performed using different combination of axes to help assess the uncertainties in the calculated velocities. A direct assessment of more than 300 data points across various operating conditions showed that the uncertainties were typically within $\pm 100 \mathrm{~m} / \mathrm{s}$ but could rise to as high as $\pm 600 \mathrm{~m} / \mathrm{s}$ for scans with low SNR (SNR just high enough to make out the presence of the peak). The uncertainty from the wavemeter and optogalvanic cell combination was \pm 50 $\mathrm{m} / \mathrm{s}$ and is much lower than the uncertainty from the noise. Scanning resolution of the laser was set sufficiently fine so as not to contribute to the total uncertainty. The effective total uncertainty was $\pm 112 \mathrm{~m} / \mathrm{s}$ for most scans and up to $\pm 600 \mathrm{~m} / \mathrm{s}$ for scans with low SNR.

\section{Results}

Axial VDFs along the discharge channel centerline for nominal RFC operations have already been reported in prior works ${ }^{20,35}$ and will not be repeated. This section will focus on updated and previously unreported results.

For the throttle points shown in this and subsequent sections, "Bb.bb" refers to the magnetic field strength applied relative to the nominal magnetic field strength. For example “300-6.3-B0.75” refers to the $300 \mathrm{~V}, 6.3 \mathrm{~kW}$ operating condition with an applied magnetic field strength that is $75 \%$ of nominal. If $\mathrm{B}$ is not shown in the label, the applied magnetic field strength was nominal. Similarly, "Pp.p" refers to the background pressure relative to the minimum pressure achieved, which was $1.2 \times 10^{-5}$ Torr. For example, "300-6.3P1.8" refers to the $300 \mathrm{~V}, 6.3 \mathrm{~kW}$ operating condition with a background pressure that is 1.8 times that of the minimum background pressure.

\section{A. Evidence of Counter-Streaming Ions near the Inner Front Pole Cover}

In prior analyses, LIF traces measured just downstream of the Inner Front Pole Cover (IFPC) show evidence of having two peaks that overlap each other. The amount of overlap and the relative heights of the two peaks varied depending on location but their presence were universal across RFCs and test segments except where the SNR was too low for the two peaks to be clearly separated. In prior analyses, the two peaks were treated as artifact of Zeeman Effect and averaged together. ${ }^{20}$ After applying the updated analysis method described earlier, the two-peak structure still remained, suggesting that each peak represented real ions. Figure 8(a) and (b) show examples of LIF data on axes 2 and 3, respectively, from near the IFPC at $\mathrm{R}=0.45, \mathrm{Z}=0.03$ (Axially slightly downstream and radially near the middle of the IFPC).

Given that the two-peak structures were found on scans of the two side-injection axes (axes 2 and 3), they can be interpreted in one of two ways. Either the left peak on axis 2 was associated with the left peak on axis 3 (and right associated with right) or the left peak on axis 2 was associated with the right peak on axis 3 . These interpretations can then
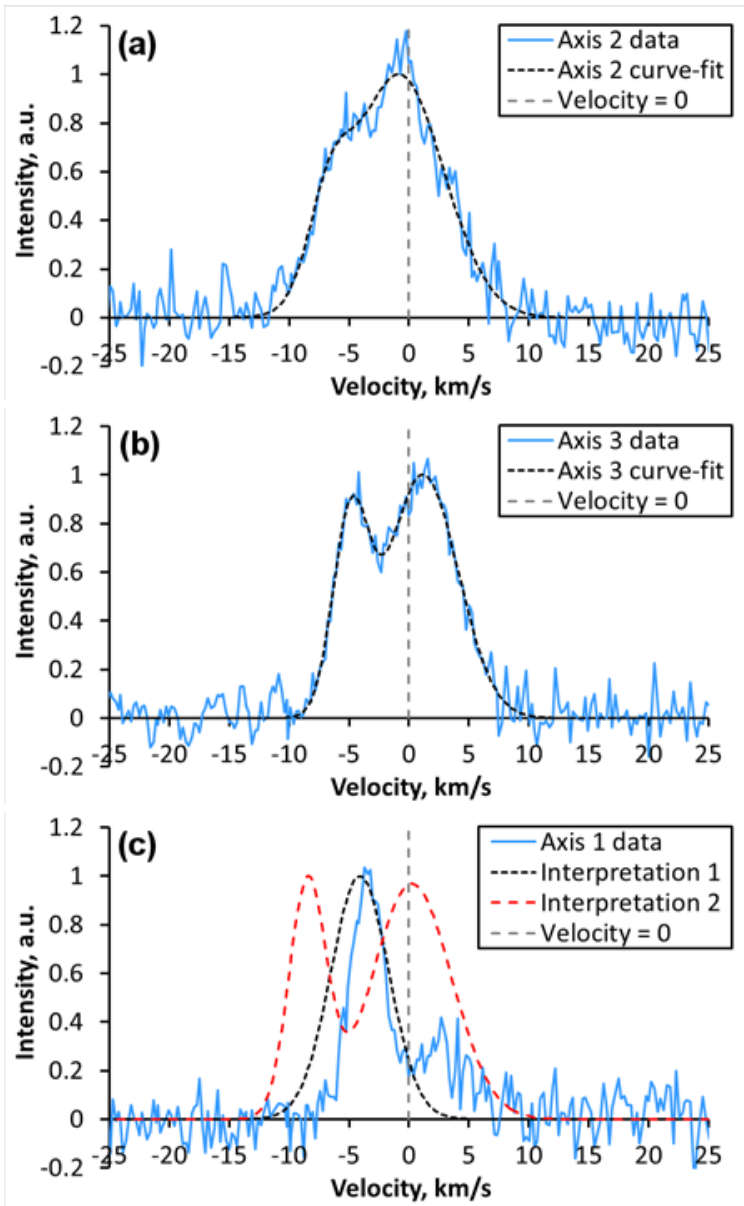

Figure 8. Examples of two-peak structures found near the IFPC on (a) axis 2, (b) axis 3. (c) shows axis 1 data with two different interpretations of axes 2 and 3 data. All data were from $600 \mathrm{~V}, 12.5 \mathrm{~kW}$ operations at the location $R=0.45, Z=0.03$. 
be used to predict the appearance of the axis 1 (axial axis) VDF. Figure 8(c) shows an example of the two interpretations plotted with the associated axis 1 data. As can be seen in this figure, interpretation 1 provided a very good fit of the average velocity and width of the dominant peak on axis 1 while interpretation 2 provided a very poor fit. Interpretation 1 corresponded to two streams of ions traveling at large oblique angles relative to the IFPC downstream surface where one stream was travelling radially inward and the other stream was travelling radially outward. Interpretation 2 corresponded to one stream traveling normal to and towards the IFPC downstream surface while the other stream was nearly stationary. This analysis was further applied to more than twenty sets of VDFs across different operating conditions and IFPC locations. In every instance, interpretation 1 provided a much better fit to the axis 1 data than interpretation 2.

Another interesting item of note was that axis 1 data contained a small peak (right of the "velocity $=0$ " line in Figure 8(c)) that was not predicted by either interpretation. This turned out to be an artifact of the fact that the pole cover was polished at the start of the test. Since axis 1 laser beam was aligned to be perpendicular to the IFPC downstream surface, some amount of the laser light was reflected by the pole cover and moved back into the interrogation zone, creating a mirror image of the dominant peak (left of the "velocity $=0$ " line in Figure 8(c)). The artificial nature of this small peak was further supported by axis 1 data taken later in the test campaign where the pole cover had roughened and there were no small peaks present. Figure 9 show an example

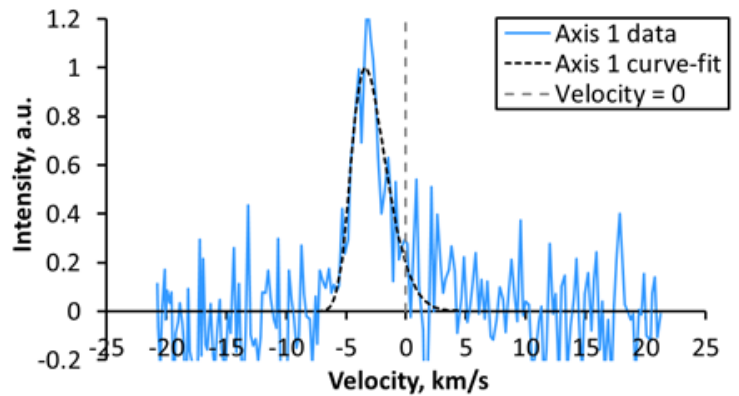

Figure 9. Axis 1 LIF data for $500 \mathrm{~V}, 10.4 \mathrm{~kW}$ operation at the location $R=0.45, Z=0.03$.

of axis 1 LIF trace taken later in the test campaign. For results presented in this paper, any small peak on axis 1 that had a velocity opposite and similar in magnitude to the dominant peak was excluded from analysis.

Once the updated analysis method was applied and IFPC data re-interpreted as two opposing streams, inconsistencies in the results shown in prior work became apparent. ${ }^{20}$ Figure 10 shows the averaged velocity vector near the IFPC for the thruster operating at $300 \mathrm{~V}, 6.3 \mathrm{~kW}$ obtained from the previous analysis method. ${ }^{20}$ Figure 11 shows the same but obtained using the updated analysis method. One ion stream was depicted with blue arrows while the other was depicted with red arrows. Note that at some locations, the SNR of the LIF traces were not high enough for the two peaks to be clearly separated, and in other cases, one peak was much more dominant. A single black arrow was plotted at each of these locations.

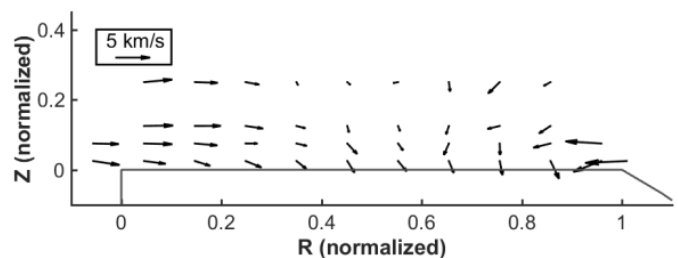

Figure 10. Averaged velocity vector near the IFPC for $300 \mathrm{~V}, 6.3 \mathrm{~kW}$ operation analyzed using the old method.

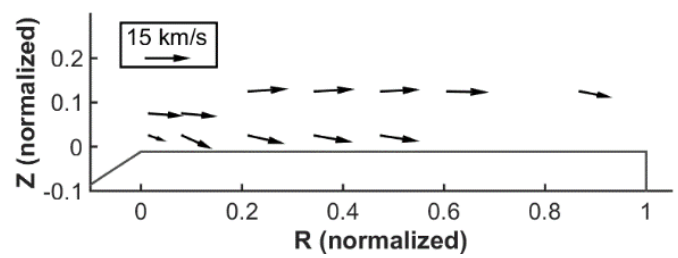

Figure 12. Averaged velocity vector near the OFPC for $300 \mathrm{~V}, 6.3 \mathrm{~kW}$ operation.

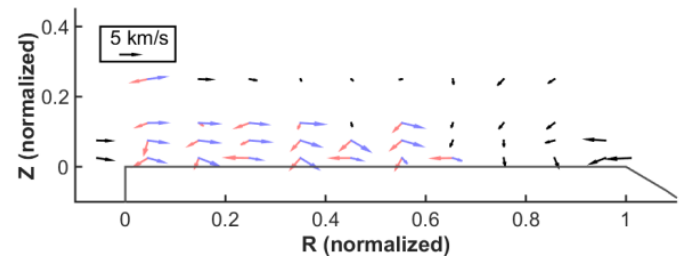

Figure 11. Averaged velocity vector near the IFPC for $300 \mathrm{~V}, 6.3 \mathrm{~kW}$ operation analyzed using the updated method.

If one were to look only at Figure 10, one might conclude that ions from two opposite directions started out moving mostly parallel to the IFPC surface but were turned into said surface by an anomalous force. While local sheath potential can draw ions into the IFPC, it does not have the ability to decelerate ions in the radial direction (to turn the direction of the ions from parallel to perpendicular). Radial deceleration would require a complex plasma potential structure that cannot develop with a conducting pole cover. Furthermore,

averaged ion velocity vector near the Outer Front Pole Cover (OFPC) (Figure 12) never displayed any obvious signs of ion turning. Additionally, the turning cannot be explained by elastic collision because the mean free path for the ions near the IFPC was on the order of 100's to 1000's of meters. 
Under the hypothesis that there were actually two streams of ions present across the entire IFPC, a different and much simpler explanation for Figure 10 can be derived. For ease of discussions, the stream of ions originating from the direction of the cathode (blue arrows pointing towards the right in Figure 11) will be referred to as the "cathode stream" while the stream of ions originating from the direction of the Fig discharge channel (red arrows pointing towards the left in streaming ions arrive at the inner front pole. Figure 11) will be referred to as the "discharge channel

stream”. Figure 13 shows a simple diagram of how counter-streaming ions arrive at the inner front pole. When velocity is averaged across two ion populations and if those populations were of constant velocities but the ratio between them varied, a figure like Figure 10 would be the natural result. Near the cathode (near $\mathrm{R}=0$ ) where the density of the cathode stream was much higher than that of the discharge channel stream, the averaged vector had the same characteristics as the cathode stream (i.e. pointing radially outward). Conversely, near the discharge channel (near $\mathrm{R}=1$ ) where the discharge channel stream dominates, the averaged vector had the same characteristics as the discharge channel stream (i.e. pointing radially inward). Near the radial middle where the densities of the two streams were comparable, the averaged vector ended up with near zero radial velocity and only the axial component was apparent, thereby appearing as if the ions had turned completely towards the IFPC.

At this point, it should be noted that two ion streams appeared in the LIF traces in part because the LIF data were obtained in the R-Z plane. In reality, ions that originated from the discharge channel were traveling from all azimuthal locations toward the interrogation point. In other words, one can expect that ions were arriving at the point of interrogation from out of the R-Z plane. However, particle density for free expansion into vacuum scales as inverse of square of distance. That is to say the part of the discharge channel nearest to the interrogation zone would always be the dominant contributor of discharge channel ions. Ions may travel from other parts of the discharge channel through the center of the thruster to the interrogation point, appearing as if they came from the same direction as the cathode ions, but their contribution was expected to be small.

Another interesting effect of the fact that ions could have come from all around the interrogation point was that the magnitude of the ion velocity might have been underestimated. Since the azimuthal component of the ion velocity was not captured in this LIF experiment, the energy and angle of incidence (AOI) with which the discharge channel stream bombarded the IFPC presented here may be lower than the actual values. With the aid of modeling and some simplifying assumptions, it may be possible to correct for this effect. The magnitude of the effect was expected to be small given the inverse of square of distance drop off in ion density and any correction is left for future work.

Although the two streams of ions near the IFPC were referred to as the "cathode stream" and "discharge channel stream", the LIF data did not uniquely establish the identity of these ions. Ions that travelled radially inward were very likely to be composed entirely of CEX ions and ions that had undergone partial acceleration from the discharge channel because there were no other sources of ions in that direction. Ions that travel radially outward could be a combination of cathode ions and discharge channel ions as described previously. There is also the possibility of ions generated by the phenomenon known as the "central spike", where Hall thrusters without centrally mounted cathodes had been observed to carry luminous spike originating from the center of the thruster. Figure 14 shows an example of the central spike. This paper will not speculate further on the origin of the cathode stream but simply assumes that cathode ions are the dominant source. Future studies into the identity of the cathode stream ions may be

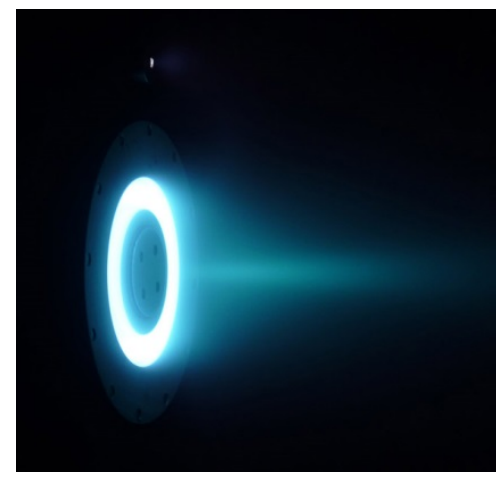

Figure 14. NASA High Voltage Hall Accelerator (HiVHAc) with a luminous central spike. beneficial.

\section{B. Implications for Pole Erosion and Comparison to Wear Measurements}

Through decades of sputter yield work, it has been established that ions impacting surfaces at high oblique angles induced higher sputter rates than ions impacting at normal incidence. ${ }^{36-38}$ If there really were two streams of ions near the IFPC each impacting at an oblique angle instead of one stream impacting at normal incidence, there should be measurable impact to the IFPC erosion rate.

A survey of literature shows that for xenon bombarding carbon (specifically graphite and pyrolytic graphite), where the surface roughness was not a control parameter, the maximum sputter yield at oblique AOI can be anywhere 
from 2.3 to 4.7 times that of at normal incidence. ${ }^{39-41}$ Furthermore, Küstner, et al., performed experiments involving bombardment of graphite with deuterium (for fusion related research) where the surface roughness of the graphite was controlled..$^{42}$ In this experiment, two grades of graphite were used: pyrolytic graphite and a grade of isotropic graphite called EK98. Both grades were polished but only pyrolytic graphite attained a high level of polish (maximum surface height difference of $0.1 \mathrm{um}^{42}$ ) because it had an orderly structure. For the isotropic graphite, the surface roughness was essentially identical before and after sputtering (maximum surface height difference of $1.5 \mathrm{um}^{42}$ ). The pertinent results of work by Küstner, et al., are summarized in Table 2.

A prominent feature of the results shown in Table 2 was that at normal incidence, isotropic graphite had a higher yield than pyrolytic graphite but the opposite was true for high AOI. Given that the pyrolytic graphite attained a high level of polish but isotropic graphite was rough from the start, the pyrolytic graphite results in Table 2 would be more similar to what was experienced by a polished pole cover while the isotropic graphite results would be more similar to a pole cover that had been eroded. In other words, Table 2. Sputter yield data for two types of graphite from Küstner, et al. ${ }^{42}$

\begin{tabular}{ccc}
\hline Graphite Type & AOI $=\mathbf{0}^{\circ}$ & AOI $=\mathbf{7 0}^{\circ}$ \\
\hline Pyrolytic & $\mathbf{0 . 0 1 1} \pm \mathbf{0 . 0 0 5}$ & $\mathbf{0 . 1 1 0} \pm \mathbf{0 . 0 2 2}$ \\
Isotropic & $\mathbf{0 . 0 2 4} \pm \mathbf{0 . 0 1 0}$ & $\mathbf{0 . 0 4 8} \pm \mathbf{0 . 0 1 8}$ \\
\hline
\end{tabular}

if the ions were bombarding a polished IFPC mostly at normal incidence, the erosion rate would increase over time. In contrast, if the ions were bombarding a polished IFPC mostly at large oblique AOI, the erosion rate would decrease over time. This prediction was in agreement with surface morphology analysis performed by Küstner, et al. ${ }^{42}$ The physical explanation is illustrated in Figure 15. For a polished pole cover under normal incidence bombardment, the AOI with respect to a local (microscopic) surface is the same as the global AOI so the overall sputter yield is relatively low (Figure 15 top left). As the surface roughens from erosion, angular features begin to develop at the microscopic level. What is normal incidence at the global level will appear to have high AOI relative to a jagged surface (Figure 15 top right). Thus, the overall sputter yield increases as the surface roughens. For a polished pole cover under high AOI bombardment, the initial sputter yield is relatively high (Figure 15 bottom left). As the surface roughens, some local features will develop in a way that reduces the local AOI, other features will become shielded by neighboring features (Figure 15 bottom right). Thus, the overall sputter yield decreases as the surface roughens.

Examination of TDU1 erosion rate data obtained by Williams, et al. during the first TDU wear test campaign show that IFPC aggregate erosion rate decreased by $40 \%$ when comparing 250 hour test segment to 1000 hour test segment, where the 1000 hour test segment followed the 250 hour test segment. ${ }^{19}$ TDU3 erosion rate data obtained by Frieman, et al., during the third TDU wear test campaign show that IFPC aggregate erosion rate decreased by 20\% when comparing measurements made at 620 hour to measurements made at 1000 hour for the same test segment. ${ }^{27}$ Aggregate erosion rate was calculated by measuring the difference in height between the start of the test segment and the time indicated, then divided by the time. The amount of reduction in erosion rate was in excess of measurement uncertainty, establishing that erosion rate was decreasing over time. The pole covers used in the wear test were also examined with a Michelson interferometer style profilometer by Mackey, et al., to obtain accurate measurements of the surface roughness before and after testing. ${ }^{43}$ The roughness of the surface of polished pole covers before wear testing was on the order of 0.1 to $0.15 \mathrm{um}$. The roughness of the surface after wear testing was $1.73 \mathrm{um}$ for 250 hours of testing and 2.26 um for 1015 hours of testing. These values were very similar to those measured by Küstner, et al., ${ }^{42}$ further establishing the relevance of work by Küstner, et al., to TDU pole cover erosion. The wear test erosion rate data strongly supported the hypothesis that IFPC was eroded by ions bombarding at large oblique AOI.

The evidence presented thus far were not without flaws. Specifically, there were four shortcomings. One, for bombarding ions, Küstner, et al., used deuterium, which could chemically react with carbon and affect the overall trend. Nevertheless, angular dependence of carbon sputter yield on incidence angle has been well established for xenon on carbon in prior studies..$^{39-41}$ Two, sputtering time used by Küstner, et al., was not reported and particle energy was $2 \mathrm{keV}$ so direct correlation between the test samples and the TDU pole covers was difficult. However, as described

American Institute of Aeronautics and Astronautics 
earlier, direct measurement of the surface roughness showed good correlation. Three, wear test erosion rates were calculated by finding the difference between start of test surface height and surface height at different time interval. These erosion rates were not instantaneous rates. However, changes in these aggregate erosion rates would have appeared to be lower than the change in instantaneous erosion rate as the pole cover eroded. In other words, the change in instantaneous erosion rate as the pole cover surface roughened should be higher than what was found in the aggregate erosion rate measurements. Four, the LIF test was performed on TDU1 in VF6 while the wear tests were performed on TDU1 and TDU3 in VF5. Much care was taken during manufacturing to ensure the two thrusters were as similar as possible. Performance and plume testing of both units in VF5 and VF6 had shown that plasma discharge behavior of the two units were essentially identical. Furthermore, the surface roughness of the pole covers were several orders of magnitude smaller than the sheath thickness. In other words, energy and direction of the ions bombarding the pole covers should be near identical for the VF5 and the VF6 testing even as the condition of the pole covers varied. Nevertheless, facility effects is not a solved problem and differences between VF5 and VF6 (e.g. background pressure and physical size) adds uncertainty to the evidence that may be resolved in a future VF5 LIF test.

\section{Magnetic Field Strength Variation Study}

During this study, the magnetic field strength was set to $0.75,1$, and 1.25 times that of the nominal magnetic field strength for the four tested RFCs. Figure 16 shows the averaged axial ion velocity along the discharge channel centerline for the magnetic field strength variation study. Each sub-figure corresponds to a different RFC. These subfigures illustrate a general trend where the acceleration zone of the thruster moved downstream at lower magnetic field strength and upstream at higher magnetic field strength. This trend was most prominent for $300 \mathrm{~V}, 6.3 \mathrm{~kW}$ and was not very prominent for $400 \mathrm{~V}, 8.3 \mathrm{~kW}$. This trend was also readily identifiable in the $500 \mathrm{~V}, 10.4 \mathrm{~kW}$ and $600 \mathrm{~V}$, $12.5 \mathrm{~kW}$ data.
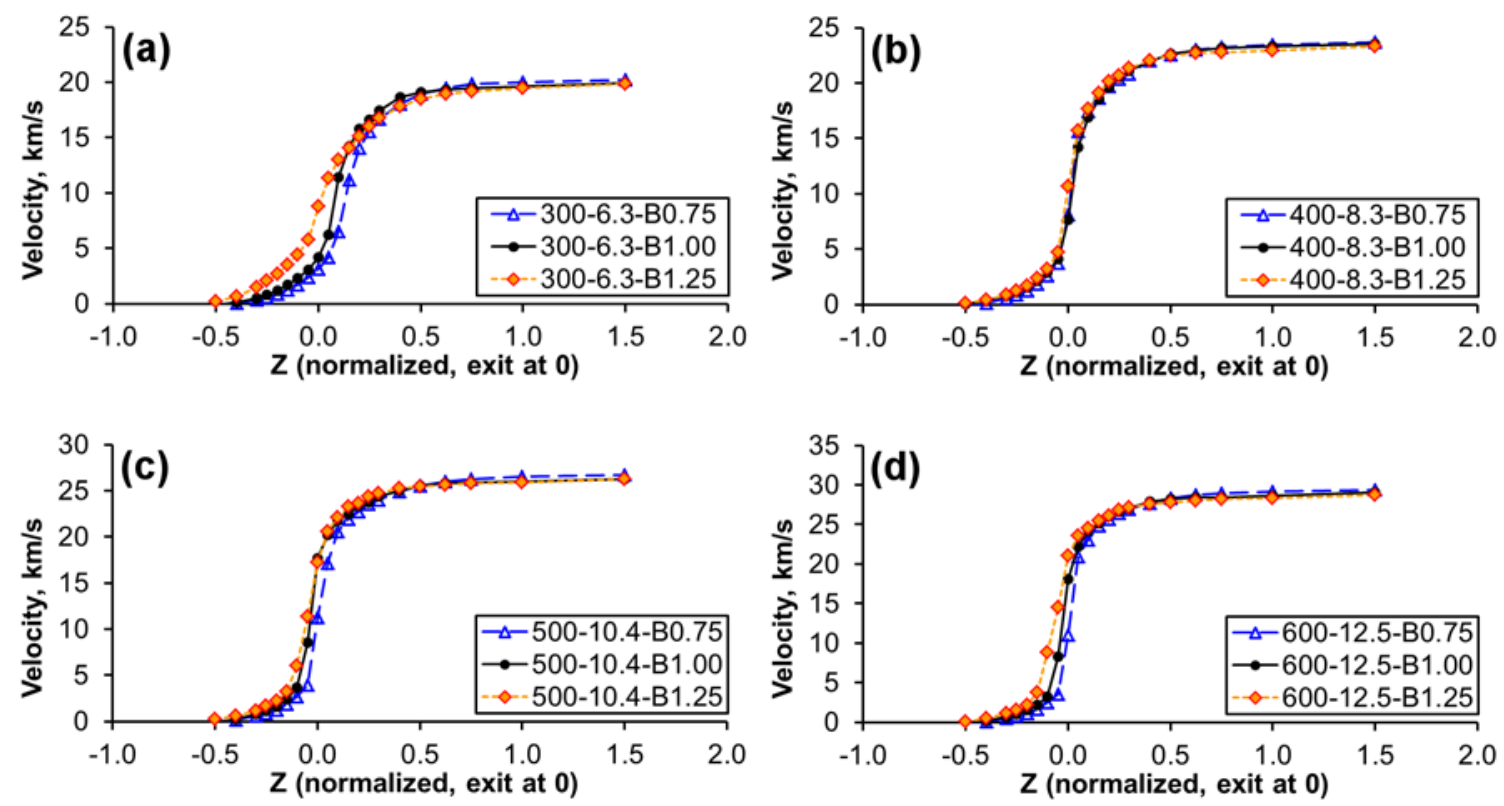

Figure 16. Averaged axial velocity along the discharge channel centerline for operations at (a) $300 \mathrm{~V}, 6.3 \mathrm{~kW}$, (b) $400 \mathrm{~V}, 8.3 \mathrm{~kW}$, (c) $500 \mathrm{~V}, 10.4 \mathrm{~kW}$, and (d) $600 \mathrm{~V}, 12.5 \mathrm{~kW}$ with different magnetic field strengths.

Figure 17 shows the averaged velocity vector near the IFPC for the thruster operating at $300 \mathrm{~V}, 6.3 \mathrm{~kW}$ and different magnetic field strengths. Figure 18 shows the same for $600 \mathrm{~V}, 12.5 \mathrm{~kW}$ operations. Figures 26 and 27 in the Appendix show the same for $400 \mathrm{~V}, 8.3 \mathrm{~kW}$ and $500 \mathrm{~V} 10.4 \mathrm{~kW}$ operations, respectively. Ion density was low downstream of the IFPC so the SNR was also low. In particular, the SNR tended to be lower towards the discharge channel due to the addition of plasma oscillations to the noise, and increased near the cathode. At some locations, SNR was not high enough for the two ion streams to be separated. However, where ion streams were separable, an interesting trend could be observed. The ion energy appeared to grow with magnetic field strength. To see the trend more clearly, a quantitative analysis was performed.

American Institute of Aeronautics and Astronautics 

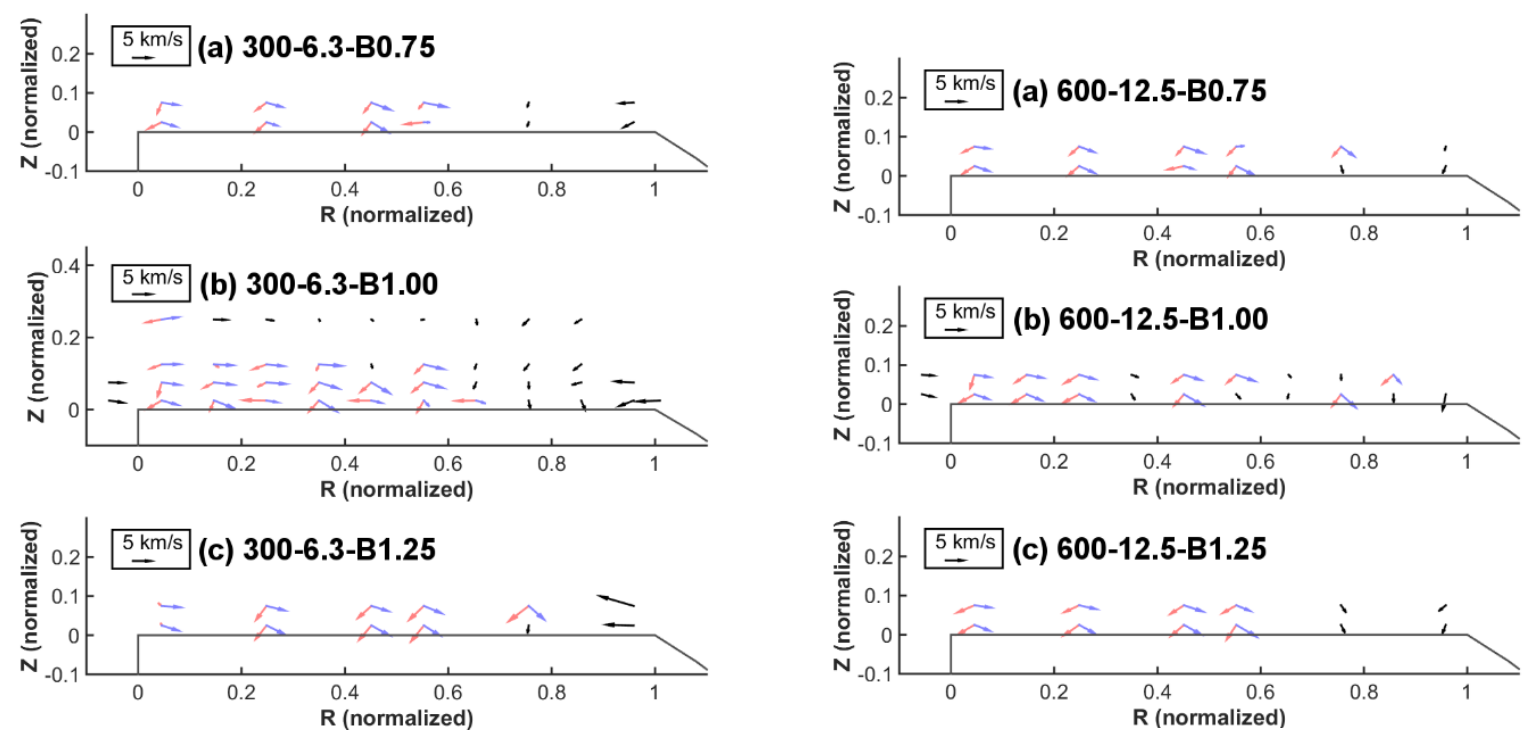

Figure 17. Averaged velocity vector near the IFPC for $300 \mathrm{~V}, 6.3 \mathrm{~kW}$ operations with (a) $0.75 \mathrm{x}$, (b) 1x, (c) $1.25 x$ nominal magnetic field strength.

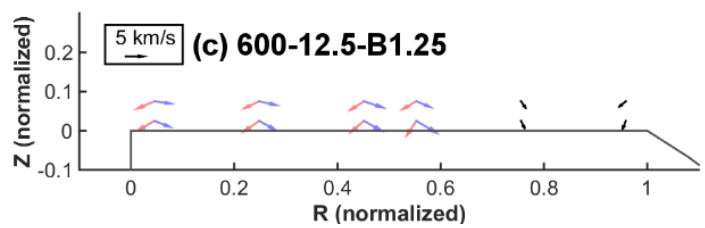

Figure 18. Averaged velocity vector near the IFPC for $600 \mathrm{~V}, 12.5 \mathrm{~kW}$ operations with (a) 0.75x, (b) 1x, (c) $1.25 x$ nominal magnetic field strength.

Table 3 summarizes the directed ion energy, FWHM energy, and angle of incidence with respect to the IFPC macro surface normal for the magnetic variation study. The directed ion energy was the magnitude of the averaged velocity converted to energy. The FWHM energy was the width of the energy distribution function as derived from the VDF measured at half of maximum intensity. This parameter was a simple way of describing the range of energies that the ions had. The majority of the ions would have energies within one FWHM energy of the mean. In fact, for a purely Gaussian distribution, 98\% of the population lies within one FWHM energy. However, past experiments (and this one as well) have shown that ion energy distributions tended to have long tails. Thus, the FWHM energy was provided here merely as a guide and not an absolute indicator. Given the low SNR for IFPC data in general, the results in this table were averaged across all locations where the two peaks could be separated for each operating condition. This approach provided better statistical confidence at a cost of spatial details.

Table 3. IFPC ion characteristics for the magnetic variation study.

\begin{tabular}{|c|c|c|c|c|c|c|c|}
\hline & & \multicolumn{3}{|c|}{ Discharge Channel Stream } & \multicolumn{3}{|c|}{ Cathode Stream } \\
\hline $\begin{array}{l}\text { Operating } \\
\text { Condition }\end{array}$ & $\begin{array}{c}\text { Sample } \\
\text { Size }\end{array}$ & $\begin{array}{c}\text { Directed } \\
\text { energy, } \\
\text { eV }\end{array}$ & $\begin{array}{c}\text { FWHM } \\
\text { energy, eV }\end{array}$ & $\begin{array}{c}\text { Averaged } \\
\text { AOI, } \\
\text { degree }\end{array}$ & $\begin{array}{c}\text { Directed } \\
\text { energy, eV }\end{array}$ & $\begin{array}{c}\text { FWHM } \\
\text { energy, eV }\end{array}$ & $\begin{array}{c}\text { Averaged } \\
\text { AOI, } \\
\text { degree }\end{array}$ \\
\hline 300-6.3-B0.75 & 8 & 13 & 27 & 42 & 17 & 34 & 70 \\
\hline 300-6.3-B1.00 & 13 & 17 & 30 & 48 & 18 & 42 & 66 \\
\hline 300-6.3-B1.25 & 9 & 23 & 63 & 35 & 23 & 43 & 62 \\
\hline 400-8.3-B0.75 & 6 & 11 & 22 & 47 & 16 & 29 & 69 \\
\hline 400-8.3-B1.00 & 9 & 14 & 27 & 45 & 15 & 37 & 66 \\
\hline 400-8.3-B1.25 & 8 & 17 & 29 & 43 & 22 & 38 & 67 \\
\hline 500-10.4-B0.75 & 10 & 12 & 18 & 39 & 11 & 31 & 67 \\
\hline 500-10.4-B1.00 & 9 & 16 & 27 & 51 & 16 & 39 & 63 \\
\hline 500-10.4-B1.25 & 8 & 17 & 34 & 53 & 18 & 43 & 70 \\
\hline 600-12.5-B0.75 & 9 & 12 & 23 & 44 & 15 & 30 & 67 \\
\hline 600-12.5-B1.00 & 11 & 16 & 28 & 43 & 18 & 38 & 61 \\
\hline 600-12.5-B1.25 & 8 & 20 & 35 & 49 & 21 & 45 & 63 \\
\hline
\end{tabular}



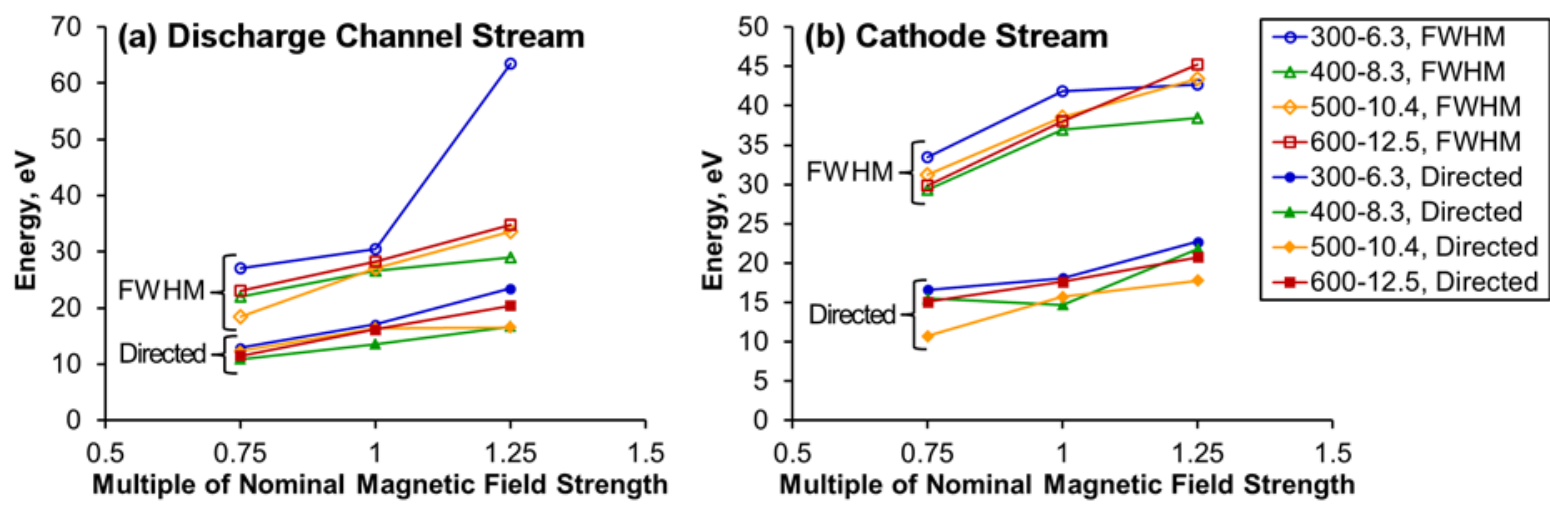

Figure 19. IFPC ion energy characteristics at different magnetic field strengths for the (a) discharge channel stream and (b) cathode stream.

Once the ion velocity data was processed as shown in Table 3, certain trends became apparent. In general, the ion energy bombarding the IFPC increased with increasing magnetic field strength. Both directed and FWHM energy increased notably with magnetic field strength. In particular, the FWHM energy of the discharge channel stream at high magnetic field strength was more than double that at nominal magnetic field strength. Figure 19 illustrates the trends in the IFPC ion energy characteristics with changing magnetic field strength. The increase in FWHM energy was important because it was an indicator of how high in energy the high-energy tail of the VDF reached. For example, for $300 \mathrm{~V}, 6.3 \mathrm{~kW}$, nominal magnetic field,

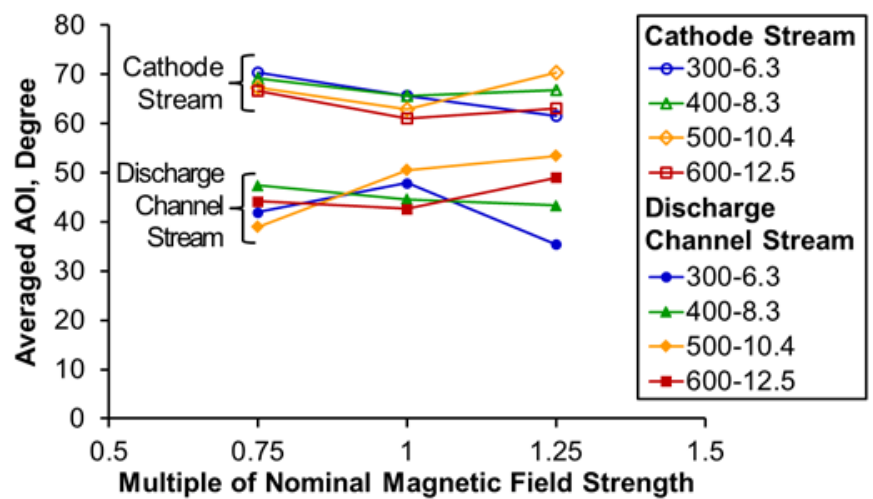

Figure 20. Angle of incidence for IFPC ions at different magnetic field strengths.

the sheath potential was around $20 \mathrm{eV}$ (Cathode-to-ground voltage was $-10 \mathrm{~V}$; plasma potential was around 10 to 12 $\mathrm{V})$. The sputtering energy associated with the averaged velocity of the discharge channel stream was $37 \mathrm{eV}(17 \mathrm{eV}$ directed energy plus $20 \mathrm{eV}$ sheath energy) while the sputtering energy associated with one FWHM away from average was $67 \mathrm{eV}$ (17 eV directed plus $30 \mathrm{eV}$ FWHM plus $20 \mathrm{eV}$ sheath). The later corresponded to a sputter yield that is about 20 times higher than the former. ${ }^{38}$ Based on the skewness of the VDFs observed near the IFPC, ions with energy in excess of $100 \mathrm{eV}$ may be present in large enough quantity to contribute meaningfully to the overall erosion rate.

Another interesting trend in Table 3 and Figure 19 was that the ions found near the IFPC were all low in energy (relative to beam energy) across all tested RFCs. Several traces were performed with long integration time constant to look for beam energy ions and nothing could be found above the noise in the data. Some examples of these traces were plotted in Figure 8. While the data present did not preclude the presence of low-intensity, high-energy ions, none had been discovered so far.

Figure 20 illustrates the trends in the angle of incidence for IFPC ions with changing magnetic field strength. Cathode stream ions were generally comparable in energy to the discharge channel stream ions. Cathode stream ions also tended to bombard the IFPC with larger AOIs than discharge channel ions. This trend can be attributed to the fact that regions of intense activity in the discharge channel extended further downstream than the same region for the cathode. Additionally, the azimuthal component of velocity could contribute to higher energy and AOI for the discharge channel stream ions. The fact that the azimuthal component of velocity was not measured meant the discharge channel stream characteristics presented here might be lower than the actual values.

Barring large changes in plasma density, the data shown in Table 3 implied that IFPC erosion rate would increase with magnetic field strength. This trend was observed in the erosion rate measurements obtained during the wear test campaigns. $^{27}$

OFPC LIF data were much more limited due to the very low SNR of the data obtained near the OFPC. This was an indicator that the ion density near the OFPC was very low. Of the tested RFCs, the most complete set of OFPC data was obtained during $300 \mathrm{~V}, 6.3 \mathrm{~kW}$ operations. In the OFPC data obtained, two-peak structure were not observed. The form of the curve-fit were either skew-normal or Gaussian.

American Institute of Aeronautics and Astronautics 
Figure 21 shows the averaged velocity vector near the OFPC for the thruster operating at $300 \mathrm{~V}, 6.3 \mathrm{~kW}$ and different magnetic field strengths. Table 4 summarizes the directed ion energy, FWHM energy, and angle of incidence with respect to the OFPC surface normal for operations at $300 \mathrm{~V}, 6.3 \mathrm{~kW}$ during the magnetic variation study. For the remaining RFCs, useable data could only be extracted at three or less locations. They will not be tabulated due to lack of statistical significance.

From Figure 21 and Table 4, one can see that the directed energy of the ions bombarding the OFPC were generally much higher than those bombarding the IFPC. Additionally, the directed energy rose with increasing magnetic field strength. On the other hand, the FWHM energy did not vary appreciably. Averaged AOI for the ions near the OFPC were generally higher than for the ions near the IFPC.

Similar to the IFPC results, barring large changes in plasma density, the data shown in Table 4 implied that OFPC erosion rate would increase with magnetic field strength. This trend was also observed in the erosion rate measurements obtained during the wear test campaigns. ${ }^{27,} 28$

\section{Background Pressure Study}

Figure 22 shows the averaged axial ion velocity along the channel centerline for the background pressure study. Each sub-figure corresponds to a different RFC. These sub-figures illustrate that the acceleration did not move by much as the background pressure varied within the tested range. While the change was small, there was a detectable movement of the acceleration zone upstream as the background pressure was increased. This could be seen in the fact that the averaged axial ion velocity was consistently higher at every location inside the acceleration zone when the background pressure was higher. Recall the velocity measurement uncertainty of this LIF diagnostics was in the range of $\pm 100 \mathrm{~m} / \mathrm{s}$. In comparison, differences of up to $2000 \mathrm{~m} / \mathrm{s}$ were detectable between operations at $1 \mathrm{X}$ versus $1.8 \mathrm{X}$ minimum background pressures.
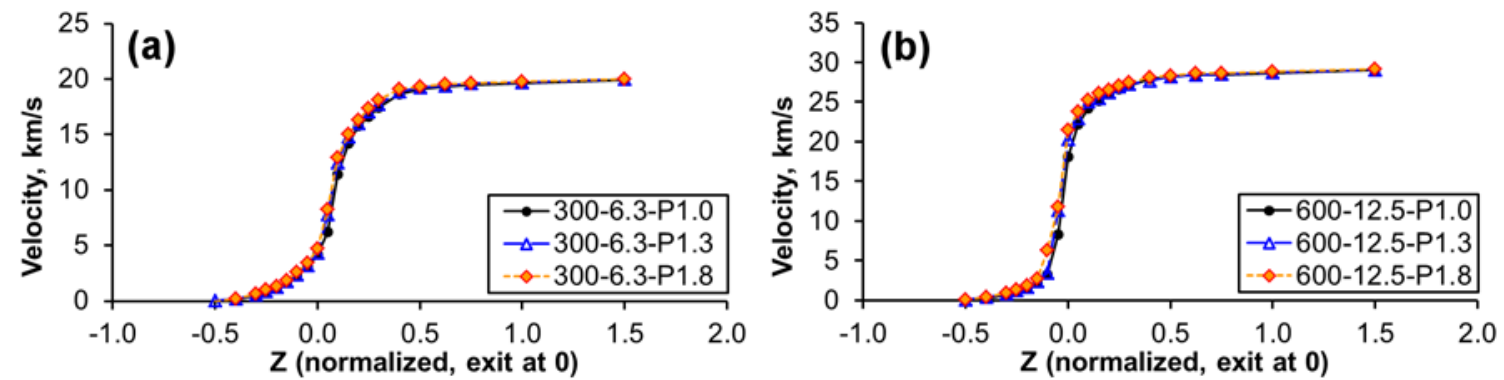

Figure 22. Averaged axial velocity along the channel centerline for operations at (a) $300 \mathrm{~V}, 6.3 \mathrm{~kW}$ and (b) 600 $\mathrm{V}, 12.5 \mathrm{~kW}$ with different background pressures.

Figure 23 shows the averaged velocity vector near the IFPC for the thruster operating at $300 \mathrm{~V}, 6.3 \mathrm{~kW}$ and different background pressures. Figure 24 shows the same for $600 \mathrm{~V}, 12.5 \mathrm{~kW}$ operations. Table 5 summarizes the directed ion energy, FWHM energy, and AOI with respect to the IFPC surface normal for the background pressure study. On average, the changes in the energy and direction of the ions near the IFPC across the tested background pressure were smaller than the changes across tested magnetic field strengths. Furthermore, low sample size for elevated pressure operations meant less reliable results. The low sample size was a result of limited test time.

American Institute of Aeronautics and Astronautics 

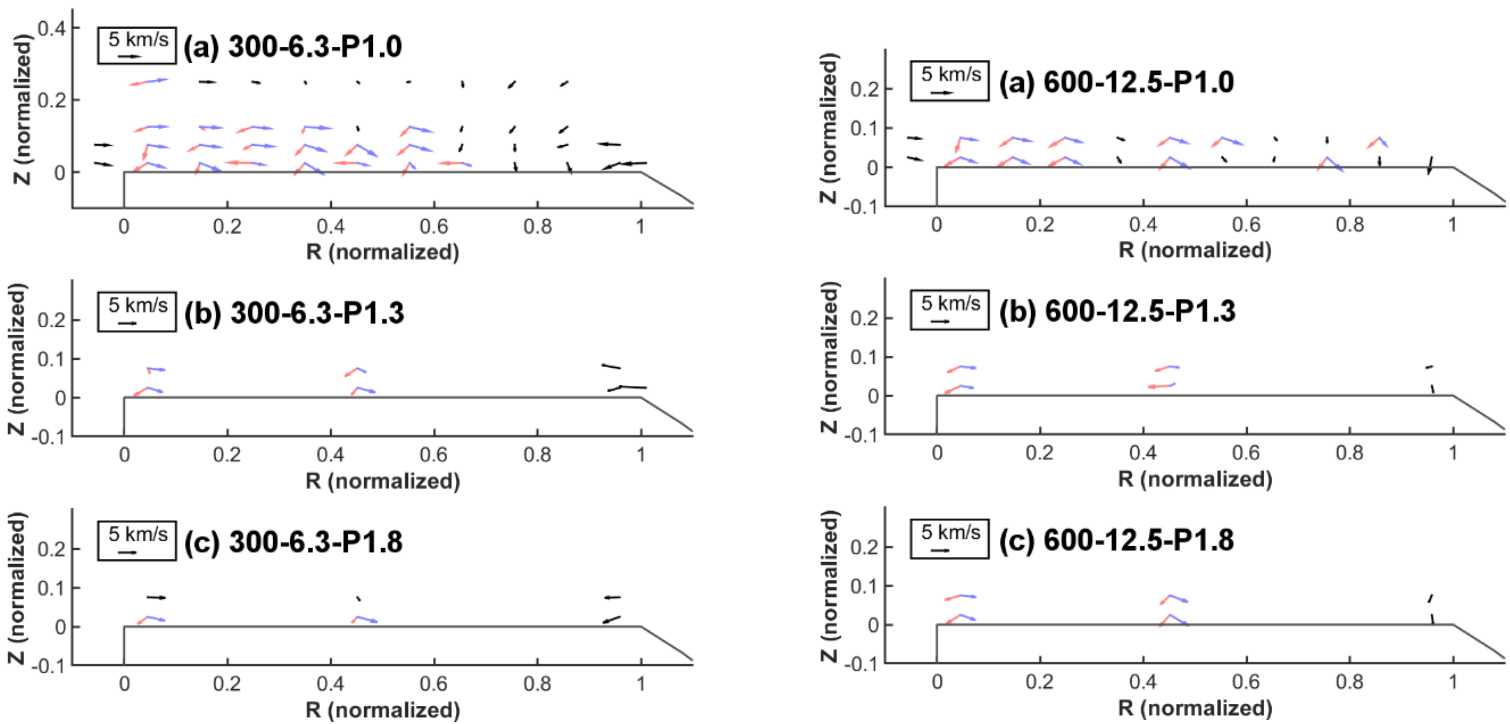

Figure 23. Averaged velocity vector near the IFPC for $300 \mathrm{~V}, 6.3 \mathrm{~kW}$ operations with (a) 1x, (b) 1.3x, (c) 1.8x minimum background pressure.

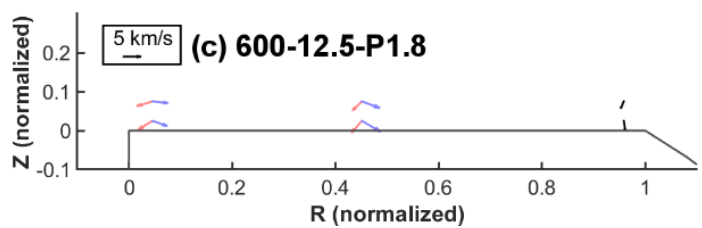

Figure 24. Averaged velocity vector near the IFPC for $600 \mathrm{~V}, 12.5 \mathrm{~kW}$ operations with (a) 1x, (b) 1.3x, (c) $1.8 x$ minimum background pressure.

Table 5. IFPC ion characteristics for the background pressure study.

\begin{tabular}{c|c|ccc|ccc}
\hline & & \multicolumn{3}{|c|}{ Discharge Channel Stream } & \multicolumn{3}{c}{ Cathode Stream } \\
\hline $\begin{array}{c}\text { Operating } \\
\text { Condition }\end{array}$ & $\begin{array}{c}\text { Sample } \\
\text { Size }\end{array}$ & $\begin{array}{c}\text { Directed } \\
\text { energy, } \\
\text { eV }\end{array}$ & $\begin{array}{c}\text { FWHM } \\
\text { energy, eV }\end{array}$ & $\begin{array}{c}\text { Averaged } \\
\text { AOI, } \\
\text { degree }\end{array}$ & $\begin{array}{c}\text { Directed } \\
\text { energy, eV }\end{array}$ & $\begin{array}{c}\text { FWHM } \\
\text { energy, eV }\end{array}$ & $\begin{array}{c}\text { Averaged } \\
\text { AOI, } \\
\text { degree }\end{array}$ \\
\hline $300-6.3-P 1.0$ & 13 & 17 & 30 & 48 & 18 & 42 & 66 \\
$300-6.3-P 1.3$ & 4 & 10 & 28 & 45 & 14 & 34 & 70 \\
$300-6.3-P 1.8$ & 2 & 8 & 22 & 72 & 22 & 35 & 72 \\
600-12.5-P1.0 & 11 & 16 & 28 & 43 & 18 & 38 & 61 \\
$600-12.5-P 1.3$ & 3 & 15 & 26 & 61 & 10 & 28 & 79 \\
600-12.5-P1.8 & 4 & 17 & 33 & 48 & 21 & 39 & 66 \\
\hline
\end{tabular}

As with the magnetic variation study, good Table 6. OFPC ion characteristics for $300 \mathrm{~V}, 6.3 \mathrm{~kW}$ operations. OFPC data were only obtainable for operations at $300 \mathrm{~V}, 6.3 \mathrm{~kW}$ due to limited SNR. Figure 25 shows the averaged velocity vector near the OFPC for the thruster operating at $300 \mathrm{~V}, 6.3$ $\mathrm{kW}$ and different background pressures. Table 6 summarizes the directed ion energy, FWHM energy, and AOI with respect to the OFPC

\begin{tabular}{|ccccc}
\hline $\begin{array}{c}\text { Operating } \\
\text { Condition }\end{array}$ & $\begin{array}{c}\text { Sample } \\
\text { Size }\end{array}$ & $\begin{array}{c}\text { Directed } \\
\text { energy, } \\
\text { eV }\end{array}$ & $\begin{array}{c}\text { FWHM } \\
\text { energy, } \\
\text { eV }\end{array}$ & $\begin{array}{c}\text { Averaged } \\
\text { AOI, } \\
\text { degree }\end{array}$ \\
\hline $300-6.3-P 1.0$ & 9 & 107 & 74 & 84 \\
\hline $300-6.3-P 1.3$ & 4 & 94 & 92 & 82 \\
\hline $300-6.3-P 1.8$ & 4 & 99 & 80 & 82 \\
\hline
\end{tabular}
surface normal for operations at $300 \mathrm{~V}, 6.3 \mathrm{~kW}$ during the background pressure study. Background pressure did not affect the OFPC ion energy and direction much over the tested pressure range. 
While this paper had made arguments that assumed ion densities did not undergo large changes, these arguments are more true for magnetic variation study, where sources of xenon neutrals were constant, than for background pressure study, where sources of xenon neutrals were varied. In particular, LIF was not effective at discriminating changes in ion densities associated with increase in CEX ion creation as background increased. While energy and direction characteristics of the ions bombarding the poles did not change appreciably with background pressure, the erosion rate could have been changing. The amount of erosion rate data at different background is currently very limited and no further conclusions will be drawn.

\section{Conclusions}

Prior analysis of the LIF data taken on the HERMeS TDU1 indicated that ions were bombarding the inner front pole cover at almost normal incidence. Based on an updated analysis method, ions near the IFPC were discovered to consist of two opposing streams in the radial-axial plane. This interpretation of the data explained contradictions described in the prior analysis of the same data. One stream of ions was likely related to the charge exchange and partially accelerated ions
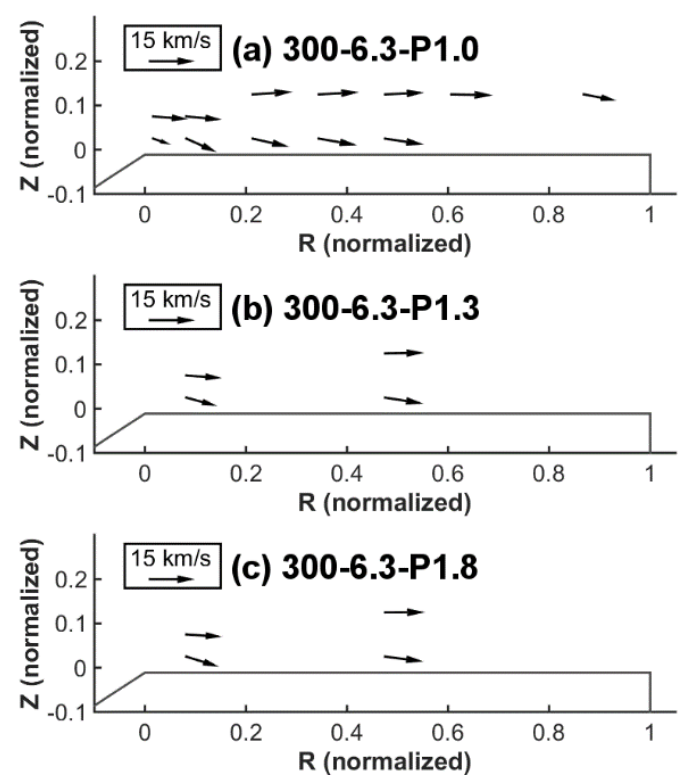

Figure 25. Averaged velocity vector near the OFPC for $300 \mathrm{~V}, 6.3 \mathrm{~kW}$ operations with (a) $1 \mathrm{x}$, (b) $1.3 \mathrm{x}$, (c) 1.8x minimum background pressure. generated in the discharge channel plasma while the other stream was likely related to the centrally mounted cathode. While directed energy of these ions were low, their spread in energy was high, reaching up to $100+\mathrm{eV}$ of effective bombardment energy. Their bombardment angles were also high, in the range of $45^{\circ}$ to $70^{\circ}$ with respect to the IFPC surface normal.

Ions near the outer front pole cover had, on average, 100 eV of directed energy, with energy reaching up to 200 $\mathrm{eV}$. These ions had large bombardment angle with respect to the OFPC surface normal. Ions near the OFPC also had low density as indicated by low LIF SNR. These ions likely originated from the discharge channel as was shown in a previous publication. $^{20}$

Survey of literature revealed that bombardment at normal incidence and large oblique incidence produce very different erosion trend. Using LIF results from the updated analysis method, predictions about wear trends were made for different surface roughness and magnetic field strengths. In particular, for normal incidence bombardment, the erosion rate of a polished graphite surface should increase over time. For large oblique incidence bombardment, the erosion rate of a polished graphite surface should decrease over time. Wear data obtained during the two wear test campaigns support the notion that the ions were bombarding the IFPC at large oblique incidence. Furthermore, LIF data implied that erosion rate increase with magnetic field strength and this was in agreement with erosion rate measurements. LIF results for the background pressure study showed relatively small changes ion energy and direction with background pressure. However, the uncertainty of the results during that study were relatively high due to the number of samples taken being relatively low.

\section{Appendix}

Figure 26 shows the averaged velocity vector near the IFPC for the thruster operating at $400 \mathrm{~V}, 8.3 \mathrm{~kW}$ and different magnetic field strengths. Figure 27 shows the same for $500 \mathrm{~V}, 10.4 \mathrm{~kW}$ operations. 

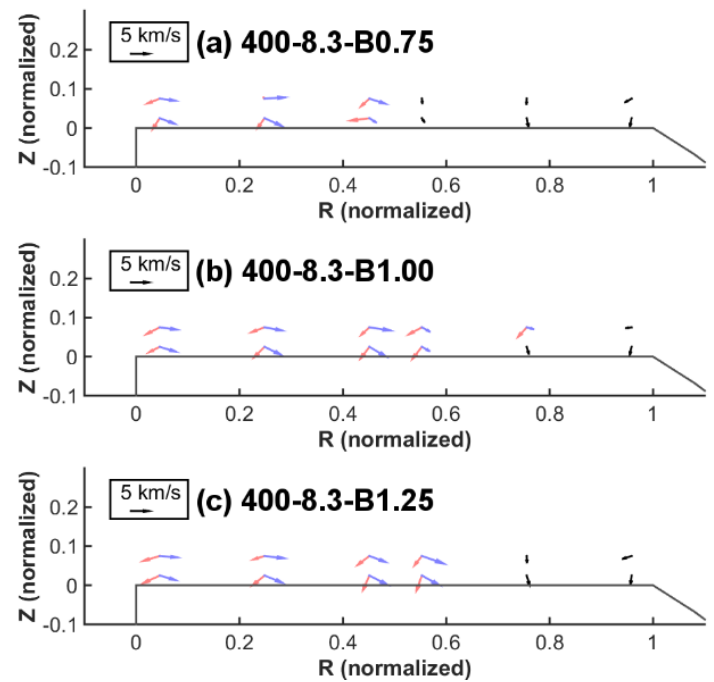

Figure 26. Averaged velocity vector near the IFPC for $400 \mathrm{~V}, 8.3 \mathrm{~kW}$ operations with (a) $0.75 x$, (b) $1 \mathrm{x}$, (c) $1.25 x$ nominal magnetic field strength.
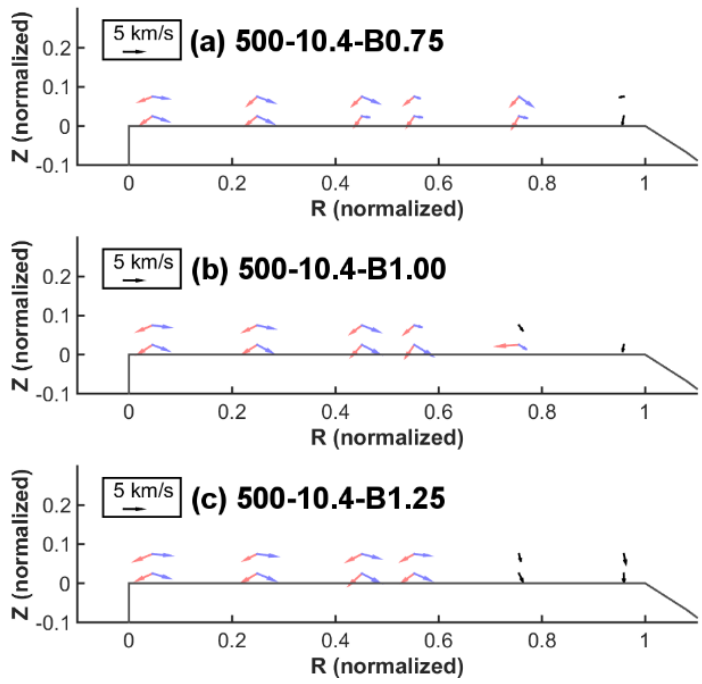

Figure 27. Averaged velocity vector near the IFPC for $500 \mathrm{~V}, 10.4 \mathrm{~kW}$ operations with (a) $0.75 \mathrm{x}$, (b) 1x, (c) $1.25 x$ nominal magnetic field strength.

\section{Acknowledgments}

The authors would like to thank the Space Technology Mission Directorate through the Solar Electric Propulsion Technology Demonstration Mission Project for funding the joint NASA GRC and JPL development of the HERMeS thruster and this work. The authors would like to thank Todd A. Tofil and Tiffany M. Morgan for managing the electric propulsion work within the SEP Project. The authors would like to thank Peter Y. Peterson and Richard R. Hofer for leading the technical work. The authors give special thanks to John T. Yim for advice and discussions on carbon sputter yield. The authors also give special thanks to Jason Frieman, Jonathan A. Mackey, and George Williams for advice and discussions on erosion rate measurements.

The authors would like to thank Christopher M. Griffiths, Thomas W. Haag, Timothy R. Sarver-Verhey, Lauren K. Clayman, James L. Myers, Li C. Chang, Dale A. Robinson, Maria Choi, Timothy G. Gray, Luis R. Pinero, Gabriel F. Benavides, James H. Gilland, Scott J. Hall, Drew M. Ahern of the NASA Glenn Research Center and James E. Polk, Ioannis G. Mikellides, Alejandro Lopez Ortega, Ryan W. Conversano, Vernon H. Chaplin of the Jet Propulsion Laboratory for work on the SEP TDM HERMeS Hall thruster. And the authors would like to thank Michael W. Swiatek, Richard G. Senyitko, Nick Lalli, Kevin L. Blake, George P. Jacynycz, Thomas A. Ralys, and Terrell J. Jensen, Michael McVetta, Luke Sorrelle, Derek Patterson, Joshua Gibson, Richard Polak for assembly of the test setup and test article as well as operation of the vacuum facility.

\section{References}

${ }^{1}$ Smith, B. K., Nazario, M. L., and Cunningham, C. C., "Solar Electric Propulsion Vehicle Demonstration to Support Future Space Exploration Missions", Space Propulsion 2012, Bordeaux, France, May 7-10, 2012.

${ }^{2}$ Congress, "National Aeronautics and Space Administration Transition Authorization Act of 2017", 2017.
${ }^{3}$ NASA
$\mathrm{HQ}$,
"Meeting
Agenda
and
Minutes",

https://www.nasa.gov/sites/default/files/atoms/files/nac heoc march 2017 public agenda revb.pdf, 2017.

${ }^{4}$ Gerstenmaier, W., "Progress in Defining the Deep Space Gateway and Transport Plan", https://www.nasa.gov/sites/default/files/atoms/files/nss chart v23.pdf, 2017.

${ }^{5}$ Manzella, D. H. and Hack, K., "High-Power Solar Electric Propulsion for Future NASA Missions", 50th AIAA/ASME/SAE/ASEE Joint Propulsion Conference, AIAA-2014-3718, doi:10.2514/6.2014-3718, Cleveland, OH, Jul 28-30, 2014.

${ }^{6}$ Herman, D. A., et al., "Overview of the Development and Mission Application of the Advanced Electric Propulsion System (AEPS)", 35th International Electric Propulsion Conference, 2017-284, Atlanta, GA, Oct 8-12, 2017.

${ }^{7}$ Hofer, R. R., et al., "Development Status of the $12.5 \mathrm{~kW}$ Hall Effect Rocket with Magnetic Shielding (HERMeS)", 35th International Electric Propulsion Conference, 2017-231, Atlanta, GA, Oct 8-12, 2017.

${ }^{8}$ Huang, W., Yim, J. T., and Kamhawi, H., "Design and Empirical Assessment of the HERMeS Hall Thruster Propellant Manifold", 62nd Joint Army-Navy-NASA-Air Force Propulsion Meeting, JANNAF-2015-3926, Nashville, TN, Jun 1-4, 2015. 
${ }^{9}$ Shastry, R., Huang, W., and Kamhawi, H., "Near-Surface Plasma Characterization of the 12.5-kW NASA TDU1 Hall Thruster", 51st AIAA/ASME/SAE/ASEE Joint Propulsion Conference, AIAA-2015-3919, doi:10.2514/6.2015-3919, Orlando, FL, Jul 27-29, 2015.

${ }^{10}$ Kamhawi, H., et al., "Performance and Facility Background Pressure Characterization Tests of NASA's 12.5-kW Hall Effect Rocket with Magnetic Shielding Thruster", 34th International Electric Propulsion Conference, 2015-007, Kobe, Japan, Jul 4-10, 2015.

${ }^{11}$ Huang, W., Kamhawi, H., and Haag, T. W., "Plasma Oscillation Characterization of NASA's HERMeS Hall Thruster via High Speed Imaging", 52nd AIAA/ASME/SAE/ASEE Joint Propulsion Conference, AIAA-2016-4829, doi:10.2514/6.2016-4829, Salt Lake City, UT, Jul 25-27, 2016.

${ }^{12}$ Kamhawi, H., et al., "Performance, Facility Pressure Effects, and Stability Characterization Tests of NASA's Hall Effect Rocket with Magnetic Shielding Thruster", 52nd AIAA/ASME/SAE/ASEE Joint Propulsion Conference, AIAA-2016-4826, doi:10.2514/6.2016-4826, Salt Lake City, UT, Jul 25-27, 2016.

${ }^{13}$ Huang, W., Kamhawi, H., Myers, J. L., Yim, J. T., and Neff, G., "Non-Contact Thermal Characterization of NASA’s HERMeS Hall Thruster", 51st AIAA/ASME/SAE/ASEE Joint Propulsion Conference, AIAA-2015-3920, doi:10.2514/6.2015-3920, Orlando, FL, Jul 27-29, 2015.

${ }^{14}$ Myers, J. L., Kamhawi, H., Yim, J. T., and Clayman, L., "Hall Thruster Thermal Modeling and Test Data Correlation", 52nd AIAA/ASME/SAE/ASEE Joint Propulsion Conference, AIAA-2016-4535, doi:10.2514/6.2016-4535, Salt Lake City, UT, Jul 25-27, 2016.

${ }^{15}$ Huang, W., Kamhawi, H., Haag, T. W., Lopez Ortega, A., and Mikellides, I. G., "Facility Effect Characterization Test of NASA's HERMeS Hall Thruster", 52nd AIAA/ASME/SAE/ASEE Joint Propulsion Conference, AIAA-2016-4828, doi:10.2514/6.20164828, Salt Lake City, UT, Jul 25-27, 2016.

${ }^{16}$ Peterson, P. Y., et al., "NASA's HERMeS Hall Thruster Electrical Configuration Characterization ", 52nd AIAA/ASME/SAE/ASEE Joint Propulsion Conference, AIAA-2016-5027, doi:10.2514/6.2016-5027, Salt Lake City, UT, Jul 25-27, 2016.

${ }^{17}$ Huang, W., et al., "Plasma Plume Characterization of the HERMeS during a 1722-hr Wear Test Campaign", 35th International Electric Propulsion Conference, 2017-307, Atlanta, GA, Oct 8-12, 2017.

${ }^{18}$ Williams, G. J., et al., "Wear Testing of the HERMeS Thruster", 52nd AIAA/ASME/SAE/ASEE Joint Propulsion Conference, AIAA-2016-5025, doi:10.2514/6.2016-5025, Salt Lake City, UT, Jul 25-27, 2016.

${ }^{19}$ Williams, G. J., et al., "Wear Trends of the HERMeS Thruster as a Function of Throttle Point", 35th International Electric Propulsion Conference, 2017-207, Atlanta, GA, Oct 8-12, 2017.

${ }^{20}$ Huang, W., Kamhawi, H., and Herman, D. A., "Ion Velocity in the Discharge Channel and Near-Field of the HERMeS Hall Thruster", 2018 Joint Propulsion Conference, AIAA-2018-4723, Cincinnati, OH, Jul 9-11, 2018.

${ }^{21}$ Kamhawi, H., Huang, W., and Mikellides, I. G., "Optimization of the Magnetic Field Topology in the Hall Effect Rocket with Magnetic Shielding", 2018 Joint Propulsion Conference, AIAA-2018-4720, Cincinnati, OH, Jul 9-11, 2018.

${ }^{22}$ Chaplin, V. H., et al., "Laser Induced Fluorescence Measurements of the Acceleration Zone in the $12.5 \mathrm{~kW}$ HERMeS Hall Thruster", 35th International Electric Propulsion Conference, 2017-229, Atlanta, GA, Oct 8-12, 2017.

${ }^{23}$ Polk, J. E., et al., "Inner Front Pole Erosion in the 12.5 kW HERMeS Hall Thruster Over a Range of Operating Conditions", 35th International Electric Propulsion Conference, 2017-409, Atlanta, GA, Oct 8-12, 2017.

${ }^{24}$ Lobbia, R. B., Conversano, R. W., Reilly, S., Hofer, R. R., and Sorensen, R., "Environmental Testing of the HERMeS TDU-2 Hall Thruster", 2018 Joint Propulsion Conference, AIAA-2018-4646, Cincinnati, OH, Jul 9-11, 2018.

${ }^{25}$ Chaplin, V. H., et al., "Spatiotemporally Resolved Ion Velocity Distribution Measurements in the $12.5 \mathrm{~kW}$ HERMeS Hall Thruster", 36th International Electric Propulsion Conference, 2019-532, Vienna, Austria, Sep 15-20, 2019.

${ }^{26}$ Kamhawi, H., et al., "Performance, Stability, and Plume Characterization of the HERMeS Thruster with Boron Nitride Silica Composite Discharge Channel", 35th International Electric Propulsion Conference, 2017-392, Atlanta, GA, Oct 8-12, 2017.

${ }^{27}$ Frieman, J. D., et al., "Long Duration Wear Test of the NASA HERMeS Hall Thruster", 2018 Joint Propulsion Conference, AIAA-2018-4645, Cincinnati, OH, Jul 9-11, 2018.

${ }^{28}$ Frieman, J. D., et al., "Completion of the Long Duration Wear Test of the NASA HERMeS Hall Thruster", 2019 Joint Propulsion Conference, Indianapolis, IN, Aug 19-22, 2019.

${ }^{29}$ Jorns, B. A., Goebel, D. M., and Hofer, R. R., "Plasma Perturbations in High-Speed Probing of Hall Thruster Discharge Chambers: Quantification and Mitigation", 51st AIAA/ASME/SAE/ASEE Joint Propulsion Conference, AIAA-2015-4006, doi:10.2514/6.2015-4006, Orlando, FL, Jul 27-29, 2015.

${ }^{30}$ Peterson, P. Y., et al., "Reconfiguration of NASA GRC’s Vacuum Facility 6 for Testing of Advanced Electric Propulsion System (AEPS) Hardware", 35th International Electric Propulsion Conference, 2017-028, Atlanta, GA, Oct 8-12, 2017.

${ }^{31}$ Yim, J. T. and Burt, J. M., "Characterization of Vacuum Facility Background Gas Through Simulation and Considerations for Electric Propulsion Ground Testing", 51st AIAA/ASME/SAE/ASEE Joint Propulsion Conference, AIAA-2015-3825, doi:10.2514/6.2015-3825, Orlando, FL, Jul 27-29, 2015.

${ }^{32}$ Huang, W., Smith, T. B., and Gallimore, A. D., "Obtaining Velocity Distribution using a Xenon Ion Line with Unknown Hyperfine Constants", 40th AIAA Plasmadynamics and Laser Conference, AIAA-2009-4226, doi:10.2514/6.2009-4226, San Antonio, Texas, Jun 22-25, 2009.

${ }^{33}$ Huang, W., Singly-Charged Xenon Zeeman Effect Study Results and Validation, in Study of Hall Thruster Discharge Channel Wall Erosion via Optical Diagnostics, University of Michigan, Ann Arbor, MI, 2011, pp. 59-62.

American Institute of Aeronautics and Astronautics 
${ }^{34}$ Huang, W., Drenkow, B., and Gallimore, A. D., "Laser-Induced Fluorescence of Singly-Charged Xenon Inside a 6-kW Hall Thruster", 45th AIAA/ASME/SAE/ASEE Joint Propulsion Conference \& Exhibit, AIAA-2009-5355, doi:10.2514/6.2009-5355, Denver, CO, Aug 2-5, 2009.

${ }^{35}$ Huang, W., Kamhawi, H., and Herman, D. A., "A Laser-Induced Fluorescence Diagnostic for HERMeS and High-Power Electric Propulsion", 65th Joint Army-Navy-NASA-Air Force Propulsion Meeting, JANNAF-2018-5669, Long Beach, CA, May 21-24, 2018.

${ }^{36}$ Sigmund, P., "Theory of Sputtering. I. Sputtering Yield of Amorphous and Polycrystalline Targets", Physical Review, Vol. 184, No. 2, doi:10.1103/PhysRev.184.383, Aug, 1969, pp. 383-416.

${ }^{37}$ Garnier, Y., Viel, V., Roussel, J. F., and Bernard, J., "Low-energy xenon ion sputtering of ceramics investigated for stationary plasma thrusters", Journal of Vacuum Science and Technology, Vol. 17, No. 6, doi:10.1116/1.582050, Nov-Dec, 1999, pp. 32463254.

${ }^{38}$ Yim, J., "A survey of xenon ion sputter yield data and fits relevant to electric propulsion spacecraft integration", 35th International Electric Propulsion Conference, 2017-060, Atlanta, GA, Oct 8-12, 2017.

${ }^{39}$ Williams, J. D., Johnson, M. L., and Williams, D. D., "Differential Sputtering Behavior of Pyrolytic Graphite and Carbon-Carbon Composite Under Xenon Bombardment", 40th AIAA/ASME/SAE/ASEE Joint Propulsion Conference, AIAA-2004-4120, doi:10.2514/6.2004-3788, Fort Lauderdale, FL, Jul 11-14, 2004.

${ }^{40}$ Kolasinski, R. D., Polk, J. E., Goebel, D. M., and Johnson, L. K., "Carbon Sputtering Yield Measurements at Grazing Incidence", 42nd AIAA/ASME/SAE/ASEE Joint Propulsion Conference \& Exhibit, AIAA-2006-4337, doi:10.2514/6.2006-4337, Sacramento, CA, Jul 9-12, 2006.

${ }^{41}$ Tartz, M., Neumann, H., Leiter, H., and Esch, J., "Pyrolytic Graphite And Carbon-Carbon Sputter Behaviour Under Xenon Ion Incidence", 29th International Electric Propulsion Conference, 2005-143, Princeton, NJ, Oct 31-Nov 4, 2005.

${ }^{42}$ Küstner, M., Eckstein, W., Dose, V., and Roth, J., "The influence of surface roughness on the angular dependence of the sputter yield", Nuclear Instruments and Methods in Physics Research B, Vol. 145, No. 3, doi:10.1016/S0168-583X(98)00399-1, 1998, pp. 320-331.

${ }^{43}$ Mackey, J. A., Frieman, J. D., Ahern, D. W., and Gilland, J. H., "Uncertainty in Electric Propulsion Erosion Measurements", 2019 Joint Propulsion Conference, Indianapolis, IN, Aug 19-22, 2019.

American Institute of Aeronautics and Astronautics 